\title{
Pitch Perfect: Vocal Pitch and the Emotional Intensity of Congressional Speech
}

\author{
BRYCE J. DIETRICH University of Iowa \\ MATTHEW HAYES Rice University \\ DIANA Z. O'BRIEN Rice University
}

\begin{abstract}
1 lthough audio archives are available for a number of political institutions, the data they provide receive scant attention from researchers. Yet, audio data offer important insights, including information about speakers' emotional states. Using one of the largest collections of natural audio ever compiled-74,158 Congressional floor speeches - we introduce a novel measure of legislators' emotional intensity: small changes in vocal pitch that are difficult for speakers to control. Applying our measure to MCs' floor speeches about women, we show that female MCs speak with greater emotional intensity when talking about women as compared with both their male colleagues and their speech on other topics. Our two supplementary analyses suggest that increased vocal pitch is consistent with legislators' broader issue commitments, and that emotionally intense speech may affect other lawmakers' behavior. More generally, by demonstrating the utility of audio-asdata approaches, our work highlights a new way of studying political speech.
\end{abstract}

$\mathbf{T}$ he analysis of increasingly vast stores of text data has transformed political science research. Scholars have used text-as-data approaches to shed new light on existing questions in American politics, comparative politics, and international relations, and to open new lines of inquiry across these subfields (Gerner et al. 1994; Grimmer 2013; Hopkins and King 2010; King and Lowe 2003; Laver, Benoit, and Garry 2003). The impact of these methods has been especially pronounced in the study of legislative politics both in the United States (e.g., Quinn et al. 2010) and abroad (e.g., Proksch and Slapin 2012). Although the development of sophisticated automated techniques for treating text as data has unlocked new and interesting sources of political information (Grimmer and Stewart 2013), to date this work has largely neglected audio data, which is stripped away in transcription. Yet, audio data contain information about an important component of (political) speech: speakers' nonverbal expressions.

In this article, we posit that it is not only what legislators say that matters but also how they say it. Drawing on well-established psychology research on

Bryce J. Dietrich (D), Assistant Professor, Department of Political Science, University of Iowa, bryce-dietrich@uiowa.edu, http://www. brycejdietrich.com.

Matthew Hayes (D), Assistant Professor, Department of Political Science, Rice University, matthew.hayes@rice.edu, http://www. matthewjhayes.com.

Diana Z. O'Brien, Albert Thomas Associate Professor Political Science, Department of Political Science, Rice University, dzobrien@ rice.edu, http://dianaobrien.com.

We are grateful to the anonymous referees at the American Political Science Review and Ken Benoit, who was an insightful and a supportive editor throughout the review process. We also thank Nichole Bauer, Logan Dancey, John Hibbing, Kris Kanthak, Joel Sievert, Danielle Thomson, and conference participants at MPSA (Chicago, IL) and CPAC (Washington University in St. Louis) for their comments and suggestions. Authors' names listed in an alphabetical order. Replication files are available at the American Political Science Review Dataverse: https://doi.org/10.7910/DVN/M4ARI7.

Received: October 21, 2017; revised: April 19, 2019; accepted: July 1, 2019. First published online: August 23, 2019. emotions and vocal communication, we argue that speakers' emotional intensity is reflected in minor changes in vocal pitch that are difficult to control. We assess this claim using one of the largest collections of natural audio ever compiled-all US House floor speeches given over a five-year period. With this previously untapped resource, we construct a novel measure of legislators' emotional intensity based on small deviations above or below a speaker's baseline vocal pitch. Coupled with corresponding text data, our measure allows for the examination of legislators' emotional intensity around different issue areas.

To develop and test our approach, we examine female House members' speech on behalf of women. Women remain significantly underrepresented in the US Congress. Legislative speech, in turn, is especially meaningful for historically marginalized groups. As well as fostering feelings of institutional trust (Mansbridge 1999), speech facilitates the link between numeric (or descriptive) and policy (or substantive) representation. Whether it is talking more about women (Pearson and Dancey 2011b) or "women's issues" (Gerrity, Osborn, and Mendez2007; Osborn and Mendez 2010), scholars have consistently shown that female representatives are more likely to elevate the voice of women both within (Pearson and Dancey 2011a) and beyond the halls of government (Herrnson, Lay, and Stokes 2003). Because female MCs have a demonstrated commitment to representing women, this issue area serves as an ideal case for examining whether this commitment is reflected in minor changes in vocal pitch that are indicative of legislators' emotional intensity. At the same time, our research also underscores, and extends our understanding of, the importance of descriptive representation in legislatures. Although male MCs can and do represent women, we posit that female legislators are able to speak about women in a way that male lawmakers generally do not.

In the sections that follow, we first make the case for studying nonverbal aspects of political speech generally, and legislators' speech in particular. In doing so, we introduce vocal pitch as a measure of underlying 
emotional intensity. Focusing on women's representation as a crucial test case, we posit that female lawmakers' speech on behalf of women will be more intense, on average, than both men's speech on women and also women's speech on other issues. To assess these claims, we draw on text and audio from all 74,158 floor speeches that are at least 50 words in length, given between 2009 and 2014 in the US House. We use the text to determine whether a representative is talking about women and the audio to capture the emotional intensity of the speech-as measured by subtle changes in the lawmaker's vocal pitch relative to her baseline. As compared with other topics, we find that female MCs are especially intense when talking about women.

Having shown that female MCs speak with greater emotional intensity when referencing women, we then offer two sets of supplementary analyses. We first examine whether increased vocal pitch is consistent with legislators' issue commitments. To do so, we begin by demonstrating that the Congresswomen who are most emotionally intense when talking about women also have voting records that are rated more favorably by women's interest groups. We then confirm that the patterns observed in female MCs' speech on women hold more generally by showing that Democratic and Republican MCs speak with heightened pitch on issues traditionally owned by their respective parties.

In our second set of extensions, we broaden our work further to provide a preliminary assessment of lawmakers' responses to the emotional intensity of floor speeches-in this case examining whether, and in what ways, male MCs react to female legislators' speech through their own speech and voting behavior. Our preliminary results suggest that as the amount and intensity of women's speech increase, Congressmen respond by talking more (and more intensely) about women. Despite concerns about backlash effects, we find that greater numbers of women's speeches delivered with heightened emotional intensity are positively associated with male MCs voting with women. Taken together, our central finding and extensions demonstrate that studying the nonverbal aspects of political speech offers new insights into important political phenomena. We thus conclude by highlighting some avenues of future research related to this new method and data source.

\section{THE NONVERBAL CONTENT OF LEGISLATIVE SPEECH}

Existing scholarship examines many forms of Congressional behavior to draw inferences about legislators' ideologies (Clinton, Jackman, and Rivers 2004; Poole and Rosenthal, 1985, 2001) and issue attention (Burden 2007; Jones, Larsen-Price and Wilkerson 2009; Sulkin 2005; Woon 2009). Although these studies provide significant insights into lawmakers' behaviors, they are limited in important ways. Roll call voting, for example, is largely constrained by party (Snyder and Groseclose 2000). Bill sponsorship is not only time consuming but also influenced by factors not easily controlled by legislators, such as staff size, seniority, and committee assignments (Schiller 1995). As a result, it is difficult to determine the issues about which MCs feel more intensely versus issue activities that are the result of party influence, constituency pressures, or institutional barriers.

We argue that legislative speech can be leveraged to gain a deeper understanding of MCs' emotional intensity around a given issue. Choosing to speak on the House floor is traditionally seen as position-taking (Mayhew 1974), and the verbal content of floor speeches has been used to estimate legislators' ideologies (Diermeier et al. 2012). Yet, floor speeches offer more than just ideological positions. In particular, the nonverbal content of a legislator's speech-specifically, her vocal pitch - captures her emotional engagement with the issue at hand.

\section{Vocal Pitch as a Measure of Emotional Intensity}

Although understudied within legislatures, the nonverbal elements of speech have clear political ramifications. A growing body of work demonstrates that vocal pitch affects evaluations of candidates (Anderson et al. 2014; Anderson and Klofstad 2012; Klofstad 2016; Klofstad, Anderson, and Nowicki 2015; Klofstad, Anderson, and Peters 2012). This research shows both that differences in baseline vocal pitch can influence candidates' political prospects and also that these effects are deeply gendered. Experimental studies, for example, suggest that citizens make inferences about competence and trustworthiness based on vocal characteristics (Anderson et al. 2014), and prefer female leaders with lower pitched voices (Klofstad, Anderson, and Peters 2012).

Despite the interest in political speech broadly, and newer work on the nonverbal elements of speech in particular, political science research has overlooked a central feature of speech: subtle variations within an individual's vocal pitch. These small deviations convey information about a speaker's emotional state. When individuals become emotionally activated, a typical physiological response is a tightening of the vocal cords. This tightening, in turn leads to a higher-than-average vocal pitch when speaking. Indeed, studies have "routinely shown that [pitch]-related measures... are influenced by affect-related arousal" (Owren and Bachorowski 2007, 240), and "higher levels of arousal have been linked to higher-pitched vocal samples" (Mauss and Robinson 2009, 222).

Although novel within political science research, the link between higher vocal pitch and emotional arousal is well established in the psychology literature. Indeed, on pages S4-S16 of our Supplemental Information, we provide an extended discussion of this link between vocal pitch and emotional intensity, including validation exercises. ${ }^{2}$ These

\footnotetext{
${ }^{1}$ It is important to note that the heightened emotional arousal indicated by increased vocal pitch does not convey complete information about a person's emotional state. Emotions can be thought of as having both valence (positive/negative or pleasant/unpleasant) and intensity (Russell 1980). Vocal pitch is a measure of the latter. Thus, we would expect vocal pitch to increase under both a state of enthusiasm as well as a state of anger. Please refer to pages S5-S6 of the SI for a fuller discussion of the relationship between vocal pitch and emotional intensity. ${ }^{2}$ Although vocal pitch is a useful measure of emotional intensity, it is not the only measure that can be used to achieve this end. See pages S15-S16 in the SI for a discussion of the benefits and limitations of our approach.
} 
include studies that generate emotional intensity via acting prompts and those that induce emotional states via the Velten procedure. Here, we note that Bachorowski and Owren (1995) induced specific emotional states within respondents by asking them to complete a 210 -trial word identification task on a computer. After each block of 10 words, the respondents received either positive ("Good Job") or negative ("Try Harder") feedback. Subjects were then asked to answer a battery of questions about their emotional state and read a block of text aloud. The authors showed that vocal pitch was higher when individuals reported higher levels of emotional intensity, leading them to conclude that pitch can be used to assess respondents' levels of emotional arousal.

These shifts in vocal pitch are subtle and difficult for the speaker to control. This physiological response, like many automatic responses, is thought to occur largely below conscious awareness. In this way, minor changes in vocal pitch serve as an "inherently honest indicator" of a speaker's "internal state" (Ekman et al. 1991, 133-4). This latter argument is supported by Zuckerman and Driver (1985), who argue that nonverbal behaviors reveal (or "leak") information that speakers are trying to hide. "Tone of voice," in particular, has been identified as an especially telling indicator. Indeed, "several studies have shown that...the tone of a person's voice leaks information that is not revealed by the verbal content or facial expressions associated with the message" (Zuckerman and Driver 1985, 129). For these reasons, verbal and nonverbal behavior can be thought of in terms of a "leakage hierarchy" with "verbal content" (i.e., the words spoken) located in the "controllable end of the continuum, whereas the body and tone of voice may be classified as less controllable and more leaky channels" (Zuckerman and Driver 1985, 130). In fact, when individuals attempt to control their vocal pitch, they often sound "more tense and less pleasant or compelling than someone speaking sincerely," which is in turn associated with "increased vocal pitch" (Elkins et al. 2014,505). ${ }^{3}$ This difficulty in controlling vocal pitch makes it uniquely well suited for studying the emotional states of strategic actors.

\footnotetext{
${ }^{3}$ Emotional deception requires deliberate effort. Whether it is a friend feigning laughter or a politician displaying anger for strategic purposes, more work is required to convince others of false feelings. Not only do such efforts require more cognitive resources, but the constant thought of whether the fabricated performance is succeeding or failing increases the stress the individual feels. This often causes those involved in emotional deception to become overly concerned with their overt behaviors. For example, a friend trying to feign laughter might inadvertently laugh too much because she does not want to be exposed as a fraud. Indeed, "deliberate attempts by liars at controlling expressive behaviors, such as attempts to control thoughts and feelings, can be the seeds of their own destruction" (DePaulo et al. $2003,78)$. This is not to say that vocal pitch is physically impossible to control for those with sufficient training in conveying emotions. For example, trained actors can successfully portray "strong" and "weak" emotions with convincing levels of "activation" and "intensity" (Laukka, Juslin, and Bresin 2005). However, especially in "deceptions which involve emotion" (Ekman et al. 1991, 133), speakers have a difficult time modulating their own vocal pitch to appear sincere. Thus, changes in vocal pitch are not only occurring largely below conscious awareness, but are also hard to fake.
}

\section{Emotional Intensity in Legislators' Speech}

Finding a reliable indicator of emotional activation or intensity is especially important in the domain of legislative speech. Scholars have long recognized that much of a legislator's behavior is best understood as strategic actions used to meet her reelection or institutional goals. That is, the verbal content of speech is often seen as cheap talk (Austen-Smith 1990). Indeed, "to the extent [that a] behavior furthers the actor's short-term self-interests," Kraut (1978) argues that we should "discount an actor's behavior as a reflection of his or her true nature." For this reason, with legislative speech, it is difficult to disentangle legislators' internal states from their strategic behavior.

Although lawmakers have ulterior motives when speaking in the legislature, some aspects of their speech may be outside their conscious control. Because "one should believe most in those aspects of a person's performance that the person is least able to deliberately and consciously control" (Kraut 1978, 381), subconscious aspects of speech should serve as more meaningful signals of legislators' emotional states. With respect to legislative speech, features like "verbal content, speech rate and fluency, most body movements, and the large easy-to-see facial expressions are all more susceptible to deliberate control" (Ekman et al. 1991,134). Speech topic, choice of words, and the length or extent of remarks each have a high degree of "controllability," and should thus be driven largely by legislators' strategic concerns. Vocal pitch, on the other hand, typically lies beyond the control of the individual (Ekman et al. 1991, 134). Because changes in pitch are less "controllable," they are a more honest indicator of a lawmaker's emotional intensity on a given issue.

This argument about the difficulty of controlling nonverbal aspects of speech has not been entirely lost on political scientists. Citing Goffman (1959), Fenno (1977) recognizes the importance of nonverbal expressions for evaluating the sincerity of legislators' behaviors. He says:

Goffman is particularly interested in the second kind of expression-"the more theatrical and contextual kind"-because he believes that the performer is more likely to be judged by others according to the nonverbal than the verbal elements of his presentation of self. Those who must do the judging, Goffman says, will think that the verbal expressions are more controllable and manipulable by the performer; and they will, therefore, read his nonverbal "signs" as a check on the reliability of his verbal "signs" (898).

When MCs speak, they do so with a combination of controllable and manipulable elements, and relatively uncontrolled and sincere elements. The less easily controlled an element, the more likely that it measures the emotional disposition the speaker has toward the issues she is advancing. There is significant evidence that changes in pitch can arise from affective arousal, and that these variations in vocal pitch are associated with other noticeable emotional displays. Because such changes in vocal pitch are difficult to purposefully manipulate, discussing 
a topic with higher-than-average vocal pitch signals one's emotional intensity about that issue. We turn now to outlining a test case for our claims about emotional intensity: women's and men's legislative speech on women.

\section{EMOTIONAL INTENSITY AND WOMEN'S REPRESENTATION}

The well-established link between women's numeric and policy representation makes Congressional speech on women an ideal test case for examining legislators' emotional intensity across policy arenas. Of course, men can (and do) act on behalf of women. Congresswomen also have a range of issue priorities, and working to represent women is not a primary concern for every female MC. Yet, scholars have pointed to a unique link between female lawmakers and female constituents, with women being more active on issues that are related to women, both within and beyond their districts (Carroll 2002). This behavior has been attributed in part to women's shared lived experiences. Reingold (1992), for example, finds that female state legislators are "more likely to express some sort of commitment to representing women and/or women's concerns," arguing that "because of their gender, they felt uniquely qualified to handle the concerns of their female constituents" (531). As compared with other topics, we thus expect that in the aggregate female lawmakers are not only more likely to talk about women but also are especially emotionally engaged when doing so.

Existing work suggests that Congresswomen do, in fact, use floor speeches to draw attention to issues related to women. Hall (1998) notes that female MCs were more active on the House floor during the Job Training Partnership Act of 1982 and on the Older Americans Act, both of which were supported by the Congressional Caucus for Women's Issues. Pearson and Dancey (2011a, 2011b) show that female legislators are not only more likely to speak on the House floor than their male colleagues but also more likely to reference women in those speeches. Osborn and Mendez (2010) likewise find that female senators speak more about health and family issues as compared with male senators. Shogan (2001) demonstrates that $11 \%$ of the statements made by female MCs mentioned the specific concerns of women, indicating that "female representatives often utilize the 'talking and deliberating' activity associated with descriptive representation to promote women's issues, interests, and concerns" (140).

Beyond the content of their speech, male and female legislators also differ in their rhetorical style, with women being especially likely to emphasize social bonds and personal experiences. Kathlene (1995) shows that female legislators are more likely than their male counterparts to emphasize the societal link to crime, leading them to speak more about long-term preventative strategies. This "connected" world view is also advanced by women in small group discussions (Karpowitz and Mendelberg 2014) and other legislative debates (e.g., Levy, Tien, and Aved 2001). Based on her analysis of floor debates on five bills in the 104th Congress, Walsh (2002) suggests that women tend to expand the frame of discussion to not only mention women but also to relate issues to their personal experiences. Swers (2002) makes similar claims. These differences in rhetorical style may also manifest in some aspects of nonverbal expression. Women, for example, use more smiling, nodding, and gazing behaviors. They also use greater facial and gestural expressiveness and smaller interpersonal distances (Hall, Carter, and Horgan 2000).

Female and male lawmakers' speech thus differs in both content and style. These differences should be especially pronounced in legislative speech referencing women. This is to be expected, given that when talking about women, female MCs can speak "with a voice carrying the authority of experience" (Mansbridge 1999, 644). Although previously unexamined, we posit that the effect of experience extends beyond content and style to influence Congresswomen's emotional intensity when referencing women. This suggests our central hypothesis: on average, female MCs speak with elevated vocal pitch when talking about women as compared with both women's average vocal pitch when discussing other topics and also men's vocal pitch when referencing women.

\section{DATA AND MEASUREMENT}

Testing our central hypothesis requires data on male and female legislators' vocal pitch when speaking about women as compared with other issue areas. To measure legislators' emotional intensity when speaking on a given topic, we turn to data from HouseLive. ${ }^{4}$ HouseLive is an online service from the Office of the Clerk that provides live and archived video of proceedings in the US House dating back to 2009 . We focus our analyses on the audio and closed-captioning text information embedded in these videos. In total, we collected 6,432 hours of audio from 863 US House debates beginning on January 6, 2009, and ending on August 4, 2014, representing the totality of debate occurring on the US House floor over those five-and-a-half years.

Having collected all floor speeches given in this time period, we split each audio file into individual speeches using the timestamps found in the closed-captioning information. Focusing on speeches that have at least 50 words yielded audio and text for 74,158 speeches. ${ }^{5}$ As we explain below, we use the audio data to extract the vocal pitch of each speech and the closed-captioning text to identify speech topic.

Importantly, in addition to contributing to Congressional scholarship, our work also provides an impressive corpus of "real-world" audio data. Past studies of emotions and vocal pitch have typically relied on either a small number of speakers induced into a particular emotional state, or trained actors asked to portray emotions (although without explicit instructions to vary their vocal pitch) (Scherer 2013). ${ }^{6}$

\footnotetext{
${ }^{4}$ http://houselive.gov.

${ }^{5}$ Speeches with under 50 words were typically procedural interjections or interruptions.

${ }^{6}$ Please see page S6 in the SI for a discussion of how deliberate portrayals of emotional intensity compare to exogenous manipulations of emotional states.
} 
Although Schuller et al. (2011) recognize the importance of actor portrayals to the study of emotion and human speech, they also argue that "obtaining more realistic data will still be the most important issue in the foreseeable future" $(1,080)$. In line with this directive, our data encompass a vast number of utterances by hundreds of speakers conveying emotional content in a natural (to them) setting. Our real-world application of vocal pitch as a marker for emotional content thus also contributes to the psychology literature on emotional activation.

\section{Measuring Emotional Intensity via Vocal Pitch}

From our raw audio data, we compute changes in speakers' vocal pitch as our measure of emotional intensity. We first calculate speakers' baseline levels of vocal pitch, and then measure variations in vocal pitch across speeches. Generally speaking, "voice pitch is the perceived 'highness' or 'lowness' of a voice and is influenced by the fundamental frequency" (Klofstad $2016,2)$. Following Titze (2000), the fundamental frequency $\left(F_{0}\right)$ can be defined using the following equation:

$$
F_{0}=\frac{1}{2 L} \sqrt{\frac{\sigma}{\rho}},
$$

where $L$ is the vocal fold length, $\sigma$ is the longitudinal stress on the vocal folds, and $\rho$ is the vocal fold tissue density. Individual variations in vocal fold length $(L)$ and density $(\rho)$ are largely determined by genetics (e.g., Debruyne et al. 2002; Przybyla, Horii, and Crawford 1992). ${ }^{7}$ Conversely, variations in longitudinal stress $(\sigma)$ are specific to the speaker and speech. Puts, Gaulin, and Verdolini $(2006,285)$ demonstrate that "[e]motional activation raises $F_{0}$ by increasing tension on the vocal fold mucosa $[\sigma$, in equation (1)], mainly via contraction of the cricothyroid muscles and consequent lengthening of the vocal folds." 8

To measure pitch, we extract the mean fundamental frequency $\left(F_{0}\right)$-that is, the average vocal pitch - from each floor speech using Praat. $^{9}$ This commonly used speech analysis software estimates the fundamental frequency by dividing the autocorrelation of a windowed signal by the autocorrelation of the window itself. ${ }^{10}$ Given that the pitch window can influence the vocal pitch estimate, on pages $\mathrm{S} 22-\mathrm{S} 30$ in the

\footnotetext{
${ }^{7}$ Additional details regarding our data can be found on pages $\mathrm{S} 3-\mathrm{S} 4$ in the Supplemental Information.

${ }^{8}$ Of course, other factors affect mean utterance pitch, including whether an utterance is a question, utterance duration, etc. However, as we show in our analyses, we find that mean vocal pitch appears to be a reliable indicator of emotional intensity even after controlling for many of these factors.

${ }^{9}$ http://www.fon.hum.uva.nl/praat/.

${ }^{10}$ Praat implements a variation of the Boersma (1993) algorithm. The software can be downloaded at: http://www.fon.hum.uva.nl/praat/. To use this software, one has to set five parameters: the pitch floor, pitch ceiling, window length, window shape, and voicing threshold. For the pitch floor and ceiling, we used Praat suggested settings, meaning for men, we set the pitch floor to $75 \mathrm{~Hz}$ and the ceiling to $300 \mathrm{~Hz}$. For women, we used a pitch range of 100 to $500 \mathrm{~Hz}$. For both the window shape and voicing threshold we used the default settings.
}

Supplemental Information, we reestimate all of our models using different Praat settings. The results remain essentially unchanged, regardless of the pitch window used.

To control for inter- and intra-speaker variations, we scale vocal pitch to standard deviations above or below the speaker's baseline. Dietrich, Enos, and Sen (2019) argue that this should be done for two reasons. First, in this project, we are not interested in whether a lawmaker generally speaks at a higher vocal pitch. Rather, we are concerned with whether a legislator's vocal pitch changes from its baseline level when speaking about women. Standardizing vocal pitch not only helps capture whether a speaker is higher or lower than her average but also gives the relative magnitude of the change. Second, although studies find few gender differences in the vocal characteristics used to convey emotions - such as laryngeal tension, lip rounding, pitch level and range, loudness, clarity, and rate (Bezooyen 1984; Brody 2009; Davitz 1964) - because women's vocal cords tend to be smaller and shorter, they do typically speak at a higher baseline vocal pitch than men. By standardizing vocal pitch using each speaker's baseline (or mean) vocal pitch, we account for this inherent sex difference.

\section{Identifying Speech Topic}

Individual-level variation in vocal pitch provides a measure of emotional intensity. We expect that levels of emotional activation vary by speech topic. We use the closed-captioning text data from HouseLive to determine whether a MC addressed women in a given speech. We opt for closed-captioned transcripts because they more accurately report what is said on the House floor than the Congressional Record. Legislators can change the Congressional Record after the fact, and often read in text that was not spoken on the House floor (e.g., asking that a letter from a constituent be added to the Congressional Record instead of reading it aloud). Because it is directly transcribed, closed-captioning information does not suffer from this limitation. ${ }^{11}$

To establish whether the speaker addressed women, we create a binary variable indicating whether the speech used any of the Pearson and Dancey (2011b) dictionary terms related to women. These include "woman," "women," "woman's," "women's," "girl,"

\footnotetext{
${ }^{11}$ As closed-captions are produced in real-time, typographical errors may be a concern. In email correspondence, the company that performs the closed-captioning service for the House of Representatives asserts that their transcribers are generally $95 \%$ accurate-i.e., $95 \%$ of words transcribed are the words actually spoken on the House floor. This assessment is based on yearly evaluations, in which the company randomly selects a certain number of transcripts from each of their transcribers and determines the degree to which those transcripts capture the floor debate for that day. For this study, we transcribed 100 randomly selected speeches. When we compared our transcribing to the closed-captioning information, the closed-captions essentially mirrored the transcripts (regardless of the similarity measure used). Based on these results and our communication with the closedcaptioning company, we are confident that the closed-captioning found on HouseLive is an accurate reflection of what is said in the US House.
} 
"girl's," "girls," "girls'," “female," "female's," "females," "females'," "servicewoman," "servicewoman's," "servicewomen," and "servicewomen's." If a speech contains any of these terms, it is coded as a 1, otherwise 0 . Given that this is a coarse measure of whether a speech addresses women, we also estimate all models using two alternative operationalizations of the dependent variable. The first considers the proportion of words in the speech drawn from these dictionary terms. The second identifies speech about women using a Structural Topic Model (STM) (Roberts et al., 2013, 2014; Roberts, Stewart, and Tingley 2014). Irrespective of the way we measure the degree to which a speech addressed women, the results are identical to those outlined below. The models using alternative approaches are reported on pages S30-S36 in the Supplemental Information.

\section{Modeling Strategy}

Our key predictor of interest is speaker sex, which we obtain from GovTrack. ${ }^{12}$ We view each speech as a unique opportunity to address women. We thus use the legislative speech (rather than the legislator) as our unit of analysis. Aggregating to the legislator level would obfuscate the important within-individual variation that takes place from speech to speech. For example, a single emotionally activated speech could artificially inflate a MC's mean vocal pitch-giving the impression that she is an emotive legislator when in reality she generally delivers subdued speeches (with one extreme exception). At the same time, because speeches given by the same MC will likely share commonalities, we estimate multilevel linear and logistic regressions with random intercepts for each legislator. This modeling approach also helps to account for other unobserved differences between legislators that could influence the parameter estimates.

We also control for other factors that may bias the results if omitted. Members who are institutionally disadvantaged are forced to take to the floor more often in an attempt to influence legislation (Maltzman and Sigelman 1996), because they have fewer other tools at their disposal. We therefore include measures of speaker race and seniority from GovTrack, and use data from Stewart and Woon $(2016)^{13}$ to determine whether the speaker was a committee chair. We also incorporate data on partisanship and ideology from Voteview, ${ }^{14}$ both of which affect floor speeches (Harris 2005; Morris 2001). For similar reasons, we include dummy variables for whether the speech was less than one minute and whether it was delivered during an election year, both of which have been shown to influence speaking behavior (Maltzman and Sigelman 1996). We also incorporate a control for the speech duration because spikes in vocal pitch will have a greater effect on mean vocal pitch when a speech is shorter. Finally, on pages S51-S86 of the

\footnotetext{
12 https://www.govtrack.us.

$13 \mathrm{http}: / /$ web.mit.edu/17.251/www/data_page.html.

$14 \mathrm{http} / / /$ voteview.com.
}

Supplemental Information, we further replicate these results with a number of different model specifications.

\section{RESULTS: LEGISLATORS' VOCAL PITCH WHEN REFERENCING WOMEN}

To begin, if the link between numeric and policy representation leads female MCs to speak with more emotional intensity about women, then we would likewise expect female MCs to speak more frequently about women than their male colleagues. We thus first establish that female lawmakers are on average more likely to talk about women in their floor speeches. In total, Congresswomen include at least one of the Pearson and Dancey (2011b) dictionary terms in 2,403 of their 13,484 total speeches $(17.82 \%)$. Male MCs, in contrast, use a dictionary term in 5,507 of 60,667 speeches $(9.08 \%)$. We further verify this expectation in Models 1.1 (Table 1, Model 1) and 1.2 (Table 1, Model 2). Here, the dependent variable is whether a given floor speech used a word from Pearson and Dancey (2011b)'s "women" dictionary. The predictor of interest is Female, which equals 1 if the $\mathrm{MC}$ is a woman and 0 otherwise. Like previous studies, our findings indicate that female legislators are, in fact, more likely to talk about women in their speeches. Based on our results from Model 1.1, women in Congress are 2.13 times more likely to reference women as compared with male MCs (predicted probabilities of 0.17 for women and 0.08 for men). This holds even after accounting for party identification, ideology, institutional position, seniority, race, and whether it was an election year (see Model 1.2).

Although this is an important finding in and of itself, it is difficult to assess the degree to which female MCs are emotionally invested in speaking about women using only the text and topics of their speeches. In Table 2, we present the mean and standard deviation of men's and women's vocal pitch by party. Here, higher values mean that the MC is speaking with greater emotional intensity. Comparing the first and second columns shows female MCs speak at a significantly higher vocal pitch when using one of the Pearson and Dancey (2011b) terms ( $t=4.14, d f=12,917, p \leq 0.001)$. More specifically, both Democratic $(t=3.12$, $d f=8,967, p \leq 0.01)$ and Republican women $(t=2.81$, $d f=3,948, p \leq 0.01$ ) have markedly higher vocal pitch when they reference women as compared with when they do not. ${ }^{15}$ The same cannot be said for male MCs, whose vocal pitch remains essentially unchanged when referencing women $(t=0.02, d f=58,281, p \leq 0.99)$. Indeed, neither Democratic $(t=-0.43, d f=25,868$, $p \leq 0.67)$ nor Republican men $(t=0.33, d f=32,411$,

\footnotetext{
${ }^{15}$ When referencing women, Republican Congresswomen have an average vocal pitch of $207.02 \mathrm{~Hz}$. Democratic Congresswomen have an average vocal pitch of $205.68 \mathrm{~Hz}$. There is no significant difference between the vocal pitch of Democratic and Republican women when speaking about women $(t=-1.02, d f=2,257, p \leq 0.31)$. This suggests that female MCs tend to generally speak at a higher vocal pitch when using at least one of the Pearson and Dancey (2011b) terms and that this difference cannot be easily attributed to party identification.
} 
TABLE 1. Female MCs More Likely to Talk About Women, with Greater Intensity

\begin{tabular}{|c|c|c|c|c|}
\hline & \multicolumn{4}{|c|}{ Dependent variable: } \\
\hline & \multicolumn{2}{|c|}{ "Women" mentioned } & \multicolumn{2}{|c|}{ Standardized vocal pitch } \\
\hline & $(1)$ & (2) & (3) & (4) \\
\hline \multicolumn{5}{|l|}{ Fixed effects } \\
\hline Constant & $\begin{array}{l}-2.427^{\star \star \star} \\
(0.035)\end{array}$ & $\begin{array}{l}-2.218^{\star \star \star} \\
(0.183)\end{array}$ & $\begin{array}{r}-0.002 \\
(0.004)\end{array}$ & $\begin{array}{l}0.151^{* * *} \\
(0.024)\end{array}$ \\
\hline Female & $\begin{array}{l}0.866^{\star * *} \\
(0.078)\end{array}$ & $\begin{array}{l}0.790^{\star * *} \\
(0.081)\end{array}$ & $\begin{array}{c}-0.017 \\
(0.011)\end{array}$ & $\begin{array}{l}-0.032^{* * *} \\
(0.011)\end{array}$ \\
\hline Democrat & & $\begin{array}{c}-0.227 \\
(0.221)\end{array}$ & & $\begin{array}{r}-0.039 \\
(0.029)\end{array}$ \\
\hline DW-nominate & & $\begin{array}{r}-0.396^{*} \\
(0.205)\end{array}$ & & $\begin{array}{c}-0.033 \\
(0.026)\end{array}$ \\
\hline Seniority & & $\begin{array}{l}-0.008^{* *} \\
(0.003)\end{array}$ & & $\begin{array}{c}0.0003 \\
(0.0004)\end{array}$ \\
\hline Committee chair & & $\begin{array}{c}0.063 \\
(0.063)\end{array}$ & & $\begin{array}{l}-0.048^{* \star *} \\
(0.014)\end{array}$ \\
\hline White & & $\begin{array}{r}-0.059 \\
(0.115)\end{array}$ & & $\begin{array}{l}0.013 \\
(0.014)\end{array}$ \\
\hline One minute & & $\begin{array}{l}-0.948^{\star * \star} \\
(0.039)\end{array}$ & & $\begin{array}{l}-0.379^{* * *} \\
(0.009)\end{array}$ \\
\hline Duration & & $\begin{array}{l}0.084^{\star \star \star} \\
(0.003)\end{array}$ & & $\begin{array}{l}0.002^{\star *} \\
(0.001)\end{array}$ \\
\hline Election year & & $\begin{array}{l}0.142^{\star \star \star} \\
(0.026)\end{array}$ & & $\begin{array}{l}-0.088^{\star * *} \\
(0.008)\end{array}$ \\
\hline $\begin{array}{l}\text { "Women" } \\
\text { mentioned }\end{array}$ & & & 0.020 & $-0.054^{\star * \star}$ \\
\hline & & & $(0.014)$ & $(0.014)$ \\
\hline $\begin{array}{l}\text { Female } \times \text { "women" } \\
\text { mentioned }\end{array}$ & & & $0.090^{\star * \star}$ & $0.112^{\star \star \star}$ \\
\hline & & & $(0.027)$ & $(0.027)$ \\
\hline $\begin{array}{l}\text { Random effects } \\
\text { MC }\end{array}$ & $\begin{array}{c}0.399 \\
(0.044)\end{array}$ & $\begin{array}{c}0.386 \\
(0.053)\end{array}$ & $\begin{array}{c}0.000 \\
(0.000)\end{array}$ & $\begin{array}{c}0.000 \\
(0.000)\end{array}$ \\
\hline $\begin{array}{l}N_{1} \\
N_{2} \\
\text { Log likelihood } \\
\text { AIC }\end{array}$ & $\begin{array}{c}74,151 \\
619 \\
-23,909.700 \\
47,825.410\end{array}$ & $\begin{array}{c}74,151 \\
619 \\
-22,786.800 \\
45,595.610\end{array}$ & $\begin{array}{c}71,198 \\
613 \\
-100,720.100 \\
201,452.100\end{array}$ & $\begin{array}{c}71,198 \\
613 \\
-99,645.100 \\
199,318.200\end{array}$ \\
\hline $\begin{array}{l}\text { Note: In Models } 1 \text { and } 2 \text {, } \\
\text { terms, } 0 \text { otherwise. The } \\
\text { speaker's vocal pitch in } \\
\text { regression. All models a } \\
{ }^{*} p<0.1 ;{ }^{* \star} p<0.05 ;{ }^{* *}\end{array}$ & $\begin{array}{l}\text { lent variable equ } \\
\text { report the results } \\
\text { viations above } \\
\text { a randomly varyir } \\
\text { Standard errors }\end{array}$ & $\begin{array}{l}\text { eech included a } \\
\text { ilevel logistic reg } \\
\text { speaker's baselir } \\
\text { or each member } \\
\text { in parentheses }\end{array}$ & $\begin{array}{l}\text { earson and Dancey } \\
\text { Models } 3 \text { and } 4, t \\
\text { models report the re } \\
\text { s. Levels of signific }\end{array}$ & $\begin{array}{l}\text { men's dictionary } \\
\text { nt variable is the } \\
\text { multilevel linear } \\
\text { orted as follows }\end{array}$ \\
\hline
\end{tabular}

$p \leq 0.75)$ significantly change their vocal pitch when talking about women. ${ }^{16}$

Moving beyond descriptive statistics, in Models 1.3 and 1.4 , we predict speaker's vocal pitch, as measured in standard deviations above or below his or her baseline. Here, positive values mean that the $\mathrm{MC}$ is speaking with more emotional intensity than we would otherwise expect, whereas the inverse is true for negative values. We test whether female MCs demonstrate greater emotional intensity when talking about women than other topics (our central hypothesis) by interacting Female with a dummy

\footnotetext{
${ }^{16}$ Additional details and other descriptive statistics can be found in Section S3 in the Supplemental Information. For a similar table comparing the mean and standard deviation of men's and women's standardized vocal pitch by party please refer to Table S3.
}

variable, indicating whether a given speech used any of Pearson and Dancey (2011b)'s dictionary terms about women ("Women" mentioned).

The significant interaction effect found in Table 1, Model 3 (Model 1.3) shows that female legislators speak with a higher vocal pitch when referencing women than when talking about other topics. When female legislators use any of the Pearson and Dancey (2011b) dictionary terms, their vocal pitch is 0.09 standard deviations higher than their baseline. This is nearly five times greater than male MCs, whose vocal pitch only increases 0.02 standard deviations when referencing women. At the same time, the raw magnitude is slight enough that this change in vocal pitch is likely beyond the control of the speaker. This finding holds even when traditional predictors of legislative behavior are included in Model 1.4, which suggests 
TABLE 2. Average Vocal Pitch and Standard Deviation for Male and Female MCs by Party

\begin{tabular}{|c|c|c|c|c|}
\hline & \multicolumn{2}{|c|}{ "Women" mentioned } & \multicolumn{2}{|c|}{ "Women" not mentioned } \\
\hline & Pitch mean & Pitch SD & Pitch mean & Pitch SD \\
\hline \multicolumn{5}{|l|}{ Male } \\
\hline Republican & 151.11 & 24.28 & 150.95 & 24.51 \\
\hline Democrat & 151.94 & 24.29 & 152.17 & 25.65 \\
\hline All & 151.50 & 24.28 & 151.49 & 25.03 \\
\hline \multicolumn{5}{|l|}{ Female } \\
\hline Republican & 207.02 & 30.27 & 203.11 & 30.52 \\
\hline Democrat & 205.68 & 25.64 & 203.35 & 28.25 \\
\hline All & 206.01 & 26.87 & 203.27 & 28.99 \\
\hline
\end{tabular}

that our measure of emotional intensity is capturing information that scholars would otherwise miss. Related work by Dietrich, O'Brien, and Yao (2019) suggests that similar results hold when analyzing word-level vocal inflections. ${ }^{17}$

Our results shed new light on the relationship between women's numeric and policy representation. Moving beyond studies that focus only on the verbal content of legislative speech, we demonstrate that women lawmakers are not only more likely to discuss women but also are more emotionally engaged on average when doing so. Of course, not all female MCs express the same level of emotional intensity when speaking about women, and some male MCs are especially emotionally engaged on this topic. There are also likely other individual-level characteristics not captured by our covariates that affect legislators' propensity to speak with intensity about women. Yet, the fact remains that even when controlling for a myriad of other factors, female MCs are more likely to speak with aboveaverage vocal pitch when referencing women than when referencing other issues and as compared with their male counterparts. Given the well-established relationship between women's numeric and policy representation, moreover, our findings support our argument that small deviations from baseline vocal pitch represent a novel measure of legislators' emotional intensity more broadly.

\section{EMOTIONAL INTENSITY AND LEGISLATORS' ISSUE COMMITMENTS}

Thus far, we have introduced a novel measure of legislators' emotional intensity and shown that female MCs, on average, are especially intense when speaking about

\footnotetext{
${ }^{17}$ Plots of these predicted probabilities with confidence intervals can be found in Figure S9 on page S45 in the Supplemental Information. We also estimated separate models for Democrats and Republicans on pages S41-S49. Tables S17 and S18 show the results for Models 1.1 and 1.2 hold for both Democrats and Republicans. However, for Models 1.3 and 1.4 the interaction between Female and "Women" Mentioned is only statistically significant for Democrats, even though the interaction is in the predicted direction for Republicans. Of course, this finding could be influenced by the comparatively smaller number of women in the Republican caucus, which makes it harder to detect an effect.
}

women. We now turn to two additional analyses that explore whether increased vocal pitch is consistent with legislators' broader issue commitments. First, we examine whether female lawmakers' vocal pitch when speaking about women is associated with their voting behavior on women's issues. Second, we assess whether our findings hold for Democratic and Republican legislators speaking on issues owned by their respective parties.

\section{Vocal Pitch and Interest Group Ratings}

If increases in vocal pitch reflect legislators' emotional intensity about a topic, then vocal pitch should be associated with other types of legislative activity related to the issue area. To this end, we examine whether female MCs' emotional intensity when speaking about women is associated with differences in voting behavior on women's issues. To do so, we use legislative scorecards from 24 prominent women's interest groups, as reported by Project Vote Smart. These scorecards are used by interest groups to inform their members about which lawmakers are more or less likely to cast votes that are consistent with the organization's mission. ${ }^{18}$ We collapse these scores into the average vote score for each legislator across all 24 groups for all available years of data, and use this information to examine voting patterns among female lawmakers.

Although on average Congresswomen speak with higher-than-baseline pitch when referencing women, Table 3 demonstrates that there is substantial variation in female MCs' emotional intensity when addressing this topic.

\footnotetext{
${ }^{18}$ Legislative scorecards typically consist of a series of legislative votes that are relevant to the interest group. If legislators voted in the group's preferred direction, then they receive a 1 (or + ), otherwise they receive a 0 (or - ). The percent of the time legislators vote in the preferred direction is their "score" which is normally standardized from 0 to 100 , with 0 being the legislator never voted in the preferred direction and a 100 being the legislator always voted in the preferred direction. More details can be found on the Project Vote Smart website (https://votesmart.org). Table S4 in the Supplemental Information (see page S21) provides the full list of groups used for the "Vote Smart" column in Table 3.
} 
Importantly, we find that the Congresswomen who speak with the greatest intensity about women receive significantly higher scores from women's interest groups than those who speak with the lowest intensity. In fact, there is a statistically significant difference between the average vote scores for the 25 most (Table $3 \mathrm{a}$ ) and least (Table 3b) activated women $(t=2.59, d f=48, p \leq 0.02)$. This suggests that the female legislators who are especially emotionally intense when referencing women also have voting records that reflect their interest in representing women.

Of course, interest groups associated with women tend to skew Democratic, so our results are likely to be stronger for female Democratic MCs. As expected, when we conducted separate tests for each party, we found a statistically significant difference between the average vote scores for the most and least emotionally intense Democratic women $(t=2.83, d f=39, p \leq 0.01)$. These results did not hold for Republican women $(t=0.14, d f=7, p>$ 0.05 ), although we note that there are far fewer observations in this category. Moreover, although falling outside of the conventional bounds of statistical significance, the most intense Republican women are still rated higher than the least intense women. Our strong findings for Democratic women-and suggestive results for Republican MCs - together offer additional support for our assertion that changes in vocal pitch can be used to capture legislators' emotional intensity around a given issue.

To further validate this claim, on pages S81-S84 in the SI, we interact our vocal pitch measure with the MC's average women's interest group rating. Here too we find that female lawmakers who tend to vote in the preferred direction of women's interest groups (as defined by Project Vote Smart) also speak with greater emotional intensity when talking about women as compared with their speech on other topics. We also replicate this analysis on pages S80-S81 in the SI with a second measure of legislative activity on behalf of women: the number of women's issue bills introduced as defined by Volden, Wiseman, and Wittmer (2018). We find that Congresswomen who introduce more women's bills also tend to speak with higher vocal pitch when referencing women than when speaking about other issues. These results are not only consistent with our broader argument but also demonstrate that vocal pitch may yield additional insights when used in conjunction with more traditional measures of substantive representation. ${ }^{19}$

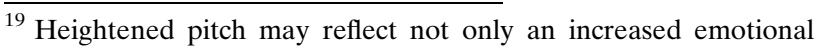
commitment to representing women, but also MCs' greater confidence in working on and speaking about women's issue bills. Indeed, people who are deeply committed to an issue are both more likely to be emotionally intense when speaking about it and more likely to develop expertise on the topic. The aim of this paper is not to disentangle emotional activation from confidence. We do note, however, that our results for female legislators hold even when accounting for other measures of confidence, including the number of women's bills introduced by each MC. We also do not observe the same relationship among male lawmakers. Even those Congressmen who were most active on women's interest bills - and thus should feel most confident with respect to this issue area-did not exhibit more emotional intensity when talking about women. Thus, although emotional intensity is undoubtedly linked to confidence and expertise, it also offers information that would not be provided by more conventional measures of these phenomena.
}

\section{Vocal Pitch and Partisan Issue Ownership}

Our work on female lawmakers suggests that we will observe heightened vocal pitch among MCs who have a broader commitment to the policy under discussion. As a further exploration of this claim, we turn now to an analysis of the speaking behavior of partisans in the US House on issues that are traditionally "owned" by the Democratic and Republican Parties. If emotional intensity is associated with legislators' issue commitments, then we should observe Democrats in Congress speaking with heightened pitch on traditionally Democratic issues as compared with both Republican issues and also those that are owned by neither party. Likewise, we expect Republicans to express greater emotional intensity when speaking about topics that are especially important to their party. To assess this claim, we examine variations in vocal pitch above or below the speaker's baseline on issues that are more likely to be associated with Democrats and Republicans.

Using a 30-topic structural topic model (STM) to categorize the content of legislative speeches (see pages S30-S32 in the Supplemental Information for more information), we select a number of topic areas that correspond to widely acknowledged partisan-owned issues. For Democratic-owned issues, we identify nine topic categories that generally correspond to broader issues related to social welfare, land management/infrastructure, and civil rights. For Republican-owned issues, we identify nine topic categories that generally correspond to defense, immigration, and budget/tax policy. ${ }^{20}$ Although it is beyond the scope of this article to resolve debates about which issues are owned by the respective parties (e.g., Petrocik 1996; Petrocik, Benoit, and Hansen 2003), these topics are widely recognized by the general public as Democratic and Republican issues (Goggin and Theodoridis 2017).

As a validation of our identification of Democraticand Republican-owned issues, we should find that legislators' speeches contain more language that falls under their party's owned issues. Indeed, we find that Republicans talk more about Republican-owned issues as compared with Democrats $(t=30.51, d f=$ $74,135, p<0.001)$, and Democrats talk more about Democratic-owned issues than Republicans $(t=18.43$, $d f=74,047, p<0.001)$. This corresponds to Democrats using $9.02 \%$ more words - and Republicans using $17.21 \%$ more words - related to their respective partyowned issues. Although these differences may seem relatively small, the topics we extract from our STM capture less than $8 \%$ of the words in a given speech on average. This is because STMs-like other forms of Latent Dirichlet Allocation (LDA) topic modelingview speeches as mixtures of several "topics," many of which are not issues but rather reflect different types of

\footnotetext{
${ }^{20}$ The top five words in each topic category can be found in Table S15 in the Supplemental Information. This table can be found on page S38. We do not include the topic associated with women in the Democraticowned issues because we use that topic as a dependent variable in Section S5.1 in the Supplemental Information. Please see Tables S10-S14 on pages S33-S37.
} 
TABLE 3. Emotionally Intense Congresswomen are Rated More Highly by Women's Interest Groups

\begin{tabular}{|c|c|c|c|c|c|c|c|c|c|}
\hline & \multicolumn{4}{|c|}{ (a) Most activated } & & \multicolumn{4}{|c|}{ (b) Least activated } \\
\hline & \multicolumn{4}{|c|}{ "Women" } & & \multicolumn{4}{|c|}{ "Women" } \\
\hline & $\begin{array}{l}\text { "Women" } \\
\text { ment. }\end{array}$ & $\begin{array}{l}\text { Not } \\
\text { ment. }\end{array}$ & $\begin{array}{l}\text { Pitch } \\
\text { diff. }\end{array}$ & $\begin{array}{l}\text { Vote } \\
\text { smart }\end{array}$ & & $\begin{array}{l}\text { "Women" } \\
\text { ment. }\end{array}$ & $\begin{array}{l}\text { Not } \\
\text { ment. }\end{array}$ & $\begin{array}{l}\text { Pitch } \\
\text { diff. }\end{array}$ & $\begin{array}{l}\text { Vote } \\
\text { smart }\end{array}$ \\
\hline \multicolumn{5}{|l|}{ Name } & \multicolumn{5}{|l|}{ Name } \\
\hline Sánchez (D-CA) & 239.58 & 208.48 & 31.10 & 67.62 & Kilpatrick (D-MI) & 189.49 & 225.66 & -36.17 & 64.55 \\
\hline Brown (D-FL) & 236.62 & 212.66 & 23.95 & 68.14 & Herrera (R-WA) & 200.15 & 221.99 & -21.85 & 38.82 \\
\hline Davis (D-CA) & 200.52 & 180.19 & 20.33 & 68.55 & $\begin{array}{l}\text { Kirkpatrick (D- } \\
\text { AZ) }\end{array}$ & 223.74 & 234.43 & -10.69 & 51.47 \\
\hline Halvorson (D-IL) & 255.86 & 236.64 & 19.22 & 52.40 & $\begin{array}{l}\text { DelBene (D- } \\
\text { WA) }\end{array}$ & 175.74 & 186.23 & -10.49 & 50.53 \\
\hline Herseth (D-SD) & 213.40 & 194.86 & 18.54 & 65.72 & Myrick (R-NC) & 208.27 & 218.32 & -10.04 & 27.43 \\
\hline Emerson (R-MO) & 205.15 & 188.06 & 17.09 & 31.46 & Negrete (D-CA) & 192.38 & 201.92 & -9.54 & 48.20 \\
\hline $\begin{array}{l}\text { Wasserman (D- } \\
\text { FL) }\end{array}$ & 203.06 & 186.04 & 17.01 & 76.17 & $\begin{array}{l}\text { McCollum (D- } \\
\text { MN) }\end{array}$ & 220.90 & 228.93 & -8.03 & 70.32 \\
\hline Lofgren (D-CA) & 207.03 & 194.45 & 12.59 & 70.26 & $\begin{array}{l}\text { Blackburn (R- } \\
\text { TN) }\end{array}$ & 250.37 & 257.36 & -6.99 & 25.42 \\
\hline Moore (D-WI) & 196.51 & 183.96 & 12.55 & 73.30 & Meng (D-NY) & 196.50 & 203.45 & -6.95 & 46.93 \\
\hline Speier (D-CA) & 215.41 & 204.95 & 10.45 & 69.46 & $\begin{array}{l}\text { Bachmann (R- } \\
\text { MN) }\end{array}$ & 213.18 & 219.18 & -6.01 & 26.79 \\
\hline Lujan (D-NM) & 224.21 & 214.10 & 10.11 & 49.53 & Bustos (D-IL) & 192.24 & 197.66 & -5.42 & 56.13 \\
\hline Brownley (D-CA) & 245.15 & 235.33 & 9.82 & 54.47 & Beatty (D-OH) & 180.63 & 185.58 & -4.94 & 51.13 \\
\hline Titus (D-NV) & 220.17 & 210.37 & 9.80 & 53.83 & Hahn (D-CA) & 212.97 & 217.84 & -4.87 & 52.07 \\
\hline Eshoo (D-CA) & 212.99 & 203.45 & 9.55 & 71.89 & Kuster (D-NH) & 226.97 & 231.75 & -4.79 & 47.80 \\
\hline Fudge (D-OH) & 194.69 & 186.40 & 8.30 & 59.30 & Harman (D-CA) & 189.46 & 193.65 & -4.19 & 65.59 \\
\hline Jenkins (R-KS) & 198.39 & 190.22 & 8.17 & 29.24 & $\begin{array}{l}\text { Hanabusa (D- } \\
\text { HI) }\end{array}$ & 210.85 & 214.89 & -4.03 & 52.81 \\
\hline Hochul (D-NY) & 208.00 & 199.84 & 8.16 & 56.25 & Noem (R-SD) & 219.65 & 223.61 & -3.96 & 31.79 \\
\hline Baldwin (D-WI) & 238.84 & 230.73 & 8.11 & 63.63 & $\begin{array}{l}\text { Shea-Porter (D- } \\
\text { NH) }\end{array}$ & 229.16 & 233.01 & -3.85 & 64.52 \\
\hline $\begin{array}{l}\text { McCarthy (D- } \\
\text { NY) }\end{array}$ & 210.95 & 203.55 & 7.40 & 64.47 & Kaptur (D-OH) & 197.61 & 201.35 & -3.73 & 66.73 \\
\hline Hartzler (R-MO) & 228.41 & 221.30 & 7.11 & 28.28 & Berkley (D-NV) & 184.68 & 188.22 & -3.54 & 66.45 \\
\hline $\begin{array}{l}\text { Dahlkemper (D- } \\
\text { PA) }\end{array}$ & 205.24 & 198.54 & 6.70 & 55.60 & Granger (R-TX) & 154.41 & 157.89 & -3.48 & 25.04 \\
\hline $\begin{array}{l}\text { Roybal-Allard } \\
\text { (D-CA) }\end{array}$ & 212.54 & 205.85 & 6.69 & 70.37 & $\begin{array}{l}\text { Duckworth (D- } \\
\text { IL) }\end{array}$ & 200.44 & 203.81 & -3.36 & 53.53 \\
\hline Frankel (D-FL) & 205.51 & 198.89 & 6.62 & 49.87 & Kelly (D-IL) & 141.00 & 144.26 & -3.26 & 33.25 \\
\hline Woolsey (D-CA) & 218.12 & 211.95 & 6.17 & 74.97 & Waters (D-CA) & 223.22 & 226.48 & -3.26 & 70.90 \\
\hline Lee (D-CA) & 199.07 & 193.04 & 6.03 & 70.34 & Kosmas (D-FL) & 185.92 & 189.12 & -3.20 & 45.90 \\
\hline \multicolumn{5}{|l|}{ Groups } & \multicolumn{5}{|l|}{ Groups } \\
\hline All & 215.82 & 203.75 & 12.06 & 59.81 & All & 200.80 & 208.26 & -7.47 & 49.36 \\
\hline Democrats & 216.52 & 204.29 & 12.24 & 63.92 & Democrats & 198.63 & 205.70 & -7.07 & 55.73 \\
\hline Republicans & 210.65 & 199.86 & 10.79 & 29.66 & Republicans & 207.67 & 216.39 & -8.72 & 29.22 \\
\hline \multicolumn{10}{|c|}{$\begin{array}{l}\text { Note: Measurements of vocal pitch are in Hertz (Hz). In the first column, we restricted our data to speeches which used at least one of the terms } \\
\text { outlined by Pearson and Dancey ( } 2011 \mathrm{~b} \text { ). In the second column, we restricted our data to speeches which did not use any of these terms. The } \\
\text { "Pitch Difference" column (abbreviated "Pitch Diff.") is the difference between these two columns. The } 25 \text { most (see Panel A) and least } \\
\text { activated (see Panel B) female MCs had the highest and lowest "Pitch Difference," respectively. The average vote score from } 24 \text { prominent } \\
\text { women's interest groups (as reported by Project Vote Smart) is found in the column labeled "Vote Smart." A full list of the groups we used can } \\
\text { be found in Table S4 in the SI. Higher values imply the MC cast more votes that are consistent with the mission of these groups. Column } \\
\text { averages for Democratic and Republican women can be found in the "Groups" section. }\end{array}$} \\
\hline
\end{tabular}

speaking styles (e.g., being more collegial or deferential). Words from a single issue are thus rare as compared to the entire corpus of words used in a speech.

Table 4 displays our results for changes in vocal pitch for Democratic- and Republican-owned issues. The positive and statistically significant interaction term in Models 4.1 and 4.2 indicates that Democrats speak with higher vocal pitch when speeches reference more Democratic-owned issues. Conversely, the statistically significant interaction term in Models 4.3 and 4.4 indicates that Republicans speak with a higher vocal pitch when speeches reference more Republicanowned issues. Moreover, the negative main effects for Democratic- and Republican-owned issues suggests that Democrats and Republicans speak at 
a significantly lower vocal pitch when referencing issues owned by the opposing party. On pages S20-S22 in the Supplemental Information, we further show that MCs who are closest to their party's median voting behavior (as measured by DW-NOMINATE scores) are more emotionally intense on their party's issues as compared with legislators who are further from the party median. ${ }^{21}$

Petrocik, Benoit, and Hansen (2003) argue that partisans have more credibility when talking about their party's issues in part "because typical Democrats (or Republicans) believe in the concerns of their party" (602). This argument is consistent with our results, as Democrats and Republicans speak with more emotional intensity when discussing their party's core issues as compared with those owned by the opposition. Moreover, the slight changes we isolate are also consistent with vocal pitch being an indicator of a lawmaker's emotional disposition toward an issue. Policy topics that are central to a party's identity should elicit a stronger emotional reaction from party members, which is exactly what we observe in the rising vocal pitch of Democrats and Republicans in Congress when discussing issues owned by their parties. 22

Heightened emotional intensity thus appears to correspond to policy commitments. Female MCs who speak at higher standard deviations above their baselines when referencing women also demonstrate their commitment to women through their voting behavior (as measured by interest group ratings). And, Democrats and Republicans speak on issues owned by their party with greater intensity than on other issues. Together, these supplementary analyses provide further evidence consistent with our claim that a legislator's vocal pitch signals her emotional intensity about the issue she is discussing.

\section{LEGISLATORS' RESPONSES TO HEIGHTENED VOCAL PITCH}

Having established that vocal pitch can be used as a measure of legislators' emotional engagement with a given issue area, we conclude our empirical analyses with a preliminary assessment of the broader

\footnotetext{
${ }^{21}$ A listing of which members are most and least activated when talking about party issues can be found in Table S5 in the Supplemental Information. This table can be found on page S23.

${ }^{22}$ This analysis also helps us rule out an alternative explanation for female legislators' heightened vocal pitch when discussing women: anxiety. Given that legislators speak with higher vocal pitch on issues owned by their party, and decreased pitch on issues owned by the opposing party, it is highly unlikely that pitch changes simply reflect lawmakers' greater anxiety when speaking about owned issues. Indeed, this would run counter to scholarship on issue ownership by Petrocik and others (Petrocik 1996; Petrocik, Benoit, and Hansen 2003), which assumes that partisans advance party issues because they are thought to be better able to handle them. In Section S8.8 of the SI, we conduct an additional analysis in which we leverage an MC's first speech in a given Congress to further demonstrate that our measure of emotional intensity is not simply picking up general anxiety about speaking on the floor of Congress.
}

implications of this speech. In particular, we ask whether emotionally intense speech by women is associated with changes in other lawmakers' behavior. MCs' floor speeches can provide information to both their constituents and also their fellow legislators. Even when lawmakers are not physically present on the floor, the rise of C-SPAN means that they are devoting more time to both giving and paying attention to floor speeches. As Kingdon (1989) notes, "it has become common for members or their staffs to listen to the debate on the set in the office, keeping one ear on the proceedings while attending to other kinds of work" (103).

Although it is impossible to say with certainty which MCs observe floor speeches, we expect that some lawmakers do hear (about) them, especially when delivered in large numbers and with emotional intensity. As a result, we believe that floor speeches have the potential to send meaningful signals to other legislators. Returning to our test case, we may be especially likely to observe effects with respect to Congresswomen's speech about women. Work on men and women in deliberative settings shows that male behavior responds to changes in women's presence and participation (Mendelberg, Karpowitz, and Oliphant 2014). Focusing on the judiciary, Boyd, Epstein, and Martin (2010) find that male judges turn to their female colleagues when deciding cases directly related to women. We may see similar effects in Congress. When a large number of female legislators talk about women, they signal that the topic will impact women in their colleagues' districts. Because constituency pressures are a powerful force shaping speaking behavior (Maltzman and Sigelman 1996), male legislators may subsequently take to the floor to discuss women as a means to address concerns that are salient to their female constituents.

The clarity of these signals should be influenced not only by the frequency with which female legislators speak but also by the intensity. Exposure to female legislators' emotionally intense speeches by and about women should activate other legislators' emotions, leading them to become more emotionally intense themselves. Moreover, whereas a single legislator speaking at a slightly higher vocal pitch may not send a very strong signal, several speeches delivered in such a way start to carry considerable weight (particularly when those speeches are delivered by women about women). That is, a large number of emotionally intense speeches delivered on the same day is not only likely to get the attention of male MCs but also may influence their behavior. ${ }^{23}$ Although providing a direct causal test of this claim is beyond the scope of this paper, below we offer suggestive evidence consistent with male legislators responding to women's speeches.

\footnotetext{
${ }^{23}$ We also test whether a single emotionally intense speech can influence a subsequent male speaker using dyadic models. These results offer further support to the findings we present below. See pages S55-S56 in the Supplemental Information for more information.
} 
TABLE 4. Partisans Talk about Party Issues with Greater Intensity

\begin{tabular}{|c|c|c|c|c|c|}
\hline \multicolumn{3}{|c|}{ (a) Democratic issues } & \multicolumn{3}{|c|}{ (b) Republican issues } \\
\hline & \multicolumn{2}{|c|}{ Dependent variable: } & & \multicolumn{2}{|c|}{ Dependent variable: } \\
\hline & \multicolumn{2}{|c|}{ Standardized Vocal pitch } & & \multicolumn{2}{|c|}{ Standardized Vocal pitch } \\
\hline & (1) & (2) & & (3) & (4) \\
\hline \multicolumn{3}{|l|}{ Fixed effects } & \multicolumn{3}{|l|}{ Fixed effects } \\
\hline Constant & $\begin{array}{l}0.022^{\star \star} \\
(0.009)\end{array}$ & $\begin{array}{l}0.177^{\star * \star} \\
(0.025)\end{array}$ & Constant & $\begin{array}{c}0.017^{*} \\
(0.009)\end{array}$ & $\begin{array}{l}0.147^{\star * \star} \\
(0.019)\end{array}$ \\
\hline Democrat & $\begin{array}{l}-0.087^{\star \star \star} \\
(0.014)\end{array}$ & $\begin{array}{c}-0.109^{\star \star *} \\
(0.031)\end{array}$ & Republican & $\begin{array}{l}-0.087^{\star * \star} \\
(0.013)\end{array}$ & $\begin{array}{c}-0.048 \\
(0.031)\end{array}$ \\
\hline Democratic issue & $\begin{array}{c}-0.090^{* * *} \\
(0.031)\end{array}$ & $\begin{array}{c}-0.138^{\star \star *} \\
(0.031)\end{array}$ & Republican issue & $\begin{array}{c}-0.084^{* *} \\
(0.035)\end{array}$ & $\begin{array}{c}-0.189^{* * *} \\
(0.035)\end{array}$ \\
\hline \multicolumn{2}{|l|}{ DW-nominate } & $\begin{array}{c}-0.029 \\
(0.026)\end{array}$ & DW-nominate & & $\begin{array}{c}-0.026 \\
(0.026)\end{array}$ \\
\hline \multicolumn{2}{|l|}{ Seniority } & $\begin{array}{c}0.0004 \\
(0.0004)\end{array}$ & Seniority & & $\begin{array}{c}0.0003 \\
(0.0004)\end{array}$ \\
\hline \multicolumn{2}{|l|}{ Committee chair } & $\begin{array}{l}-0.046^{\star \star \star} \\
(0.014)\end{array}$ & Committee chair & & $\begin{array}{l}-0.047^{\star \star \star} \\
(0.014)\end{array}$ \\
\hline \multicolumn{2}{|l|}{ Female } & $\begin{array}{r}-0.019^{*} \\
(0.010)\end{array}$ & Female & & $\begin{array}{r}-0.017^{\star} \\
(0.010)\end{array}$ \\
\hline \multicolumn{2}{|l|}{ White } & $\begin{array}{c}0.013 \\
(0.014)\end{array}$ & White & & $\begin{array}{l}0.016 \\
(0.014)\end{array}$ \\
\hline \multicolumn{2}{|l|}{ One minute } & $\begin{array}{l}-0.377^{\star \star \star} \\
(0.009)\end{array}$ & One minute & & $\begin{array}{l}-0.377^{\star \star \star} \\
(0.009)\end{array}$ \\
\hline \multicolumn{2}{|l|}{ Duration } & $\begin{array}{c}0.002 \\
(0.001)\end{array}$ & Duration & & $\begin{array}{c}0.002^{*} \\
(0.001)\end{array}$ \\
\hline \multicolumn{2}{|l|}{ Election year } & $\begin{array}{l}-0.088^{\star \star \star} \\
(0.008)\end{array}$ & Election year & & $\begin{array}{l}-0.088^{\star \star \star} \\
(0.008)\end{array}$ \\
\hline \multirow[t]{2}{*}{$\begin{array}{l}\text { Democrat } \times \text { democratic } \\
\text { issues }\end{array}$} & $0.328^{\star \star \star}$ & $0.288^{\star \star \star}$ & $\begin{array}{l}\text { Republican } \times \text { republican } \\
\text { issues }\end{array}$ & $0.380^{\star * *}$ & $0.355^{\star \star \star}$ \\
\hline & $(0.045)$ & $(0.044)$ & \multicolumn{3}{|l|}{ Random effects } \\
\hline $\begin{array}{l}\text { Random effects } \\
\text { MC }\end{array}$ & $\begin{array}{c}0.000 \\
(0.000)\end{array}$ & $\begin{array}{c}0.000 \\
(0.000)\end{array}$ & MC & $\begin{array}{l}0.000 \\
(0.000)\end{array}$ & $\begin{array}{c}0.000 \\
(0.000)\end{array}$ \\
\hline $\begin{array}{l}N_{1} \\
N_{2} \\
\text { Log likelihood } \\
\text { AIC }\end{array}$ & $\begin{array}{c}71,197 \\
613 \\
-100,699.200 \\
201,410.400\end{array}$ & $\begin{array}{c}71,197 \\
613 \\
-99,632.380 \\
199,292.800\end{array}$ & $\begin{array}{l}N_{1} \\
N_{2} \\
\text { Log likelihood } \\
\text { AIC }\end{array}$ & $\begin{array}{c}71,197 \\
613 \\
-100,686.500 \\
201,385.000\end{array}$ & $\begin{array}{c}71,197 \\
613 \\
-99,625.450 \\
199,278.900\end{array}$ \\
\hline \multicolumn{6}{|c|}{$\begin{array}{l}\text { Note: The dependent variable is the speaker's vocal pitch in standard deviations above or below the speaker's baseline. In Panel A, we consider } \\
\text { whether Democrats tend to raise their vocal pitch when speaking aboutDemocratic-owned issues. In Panel B, we consider whether Republicans } \\
\text { tend to raise their vocal pitch when speaking about Republican-owned issues. The issues themselves are derived from the Structural Topic } \\
\text { Model (STM) outlined on pages } \mathrm{S} 30-\mathrm{S} 32 \text { in the Supplemental Information. All models are multilevel linear regressions and include randomly } \\
\text { varying intercepts for each member of Congress. Levels of significance are reported as follows: }{ }^{*} p<0.1 ;{ }^{* \star} p<0.05 ;{ }^{* \star *} p<0.01 \text {. Standard errors } \\
\text { are reported in parentheses. }\end{array}$} \\
\hline
\end{tabular}

\section{Amount and Intensity of Men's Speech on Women}

To examine men's response to female MCs' speech on women, we first extend our main analysis to consider men's willingness to address women in their floor speeches (see Table 5). In Models 5.1 and 5.2, the dependent variable is whether a given Congressman's floor speech contained one of Pearson and Dancey's (2011b) women's dictionary terms. Our primary independent variables are (1) the number of speeches delivered by women on a given legislative day that reference women (Female Speeches), and (2) the average vocal pitch of those speeches (Female Pitch). We are thus interested in the interaction between Female Speeches and Female Pitch. A positive and statistically significant interaction term would be consistent with male MCs becoming more likely to mention women when female MCs deliver a large number of speeches about women at an increased vocal pitch.

We restrict our analysis to male MCs who delivered speeches on the same legislative day as female speeches about women for which we have vocal pitch data. This restriction allows us to focus on those male 
legislators who are most likely to have been influenced by Congresswomen's behavior. ${ }^{24} \mathrm{We}$ also include two additional controls for the types of issues being debated on a given legislative day. First, we want to isolate the impact of female MCs' speech from the general effects of women's heightened issue activity. To do so, we draw on Volden, Wiseman, and Wittmer's (2018) "women's issues" measure to include a variable counting the number of bills debated in their six "women's issues" categories. ${ }^{25}$ This provides a general proxy for whether issues highly salient to women in Congress appeared on the day's agenda. Second, we are concerned that both male and female MCs may speak with greater emotional intensity when important issues are being debated. In these instances, we would expect the vocal pitch of male and female legislators to be heightened, leading to the impression that women's speech is influencing male behavior when in reality both groups are responding to the importance of the issue itself. To account for this possibility, we use $C Q$ Weekly's "Bills to Watch" ${ }^{26}$ to create a count variable of the number of major bills debated on each legislative day. ${ }^{27}$

Our results are in line with what we would expect if women's speeches influence male legislators' discussion of women. Although the interaction term in Model 5.1 is not statistically significant at the $0.05-$ level, calculating predicted probabilities suggests that vocal pitch can have a substantively meaningful effect on whether a male MC mentions women in his

\footnotetext{
${ }^{24}$ Although we acknowledge that we cannot be sure that all male MCs who spoke on the same day were in the chamber for their female colleagues' speeches, we believe that this is the most appropriate modeling strategy. No data is available on which legislators are physically present during floor speeches, and including all male MCs who served during that Congress would introduce needless noise. Moreover, even if male legislators who spoke on the same day were not physically present during their female colleagues' speeches, they should be more attuned to the happenings on the floor via C-SPAN or other methods.

${ }^{25}$ Volden, Wiseman, and Wittmer (2018) identify women's issues as those that "women in Congress are more likely than men to raise," and that women raise "in a greater volume" than men (682). Using the Policy Agendas Project, they classify all bills into 19 major topic areas. They find six topics in which significantly more bills are introduced by women than by men: (1) Health, (2) Labor, Employment, and Immigration, (3) Housing and Community Development, (4) Civil Rights and Liberties, (5) Education, and (6) Law, Crime, and Family. ${ }^{26}$ Although there are a variety of ways to operationalize this concept, we used the Congressional Quarterly (CQ) measure because the major bills it highlights also typically receive more media coverage than non$C Q$ bills, which should in turn bolster the potential electoral benefits of speaking on the issue.

${ }^{27}$ We further note that neither the number of Women' s Bills nor $\mathrm{CQ} \mathrm{Bills}$ is meaningfully associated with female vocal pitch. Although the correlation between women's vocal pitch and these measures is statistically significant $(t=-2.42, d f=61,888, p<0.05$ and $t=5.82, d f=61,888, p<0.05)$, the magnitude of the relationship is so small that we do not find it to be substantively compelling. We found a slightly larger-yet still substantively small-correlation between our two bill measures and the number of female speeches delivered ( $\rho$ $=0.14,0.08$ for Women' $\mathrm{s}$ Bills and CQ Bills, respectively). We take this as evidence that changes in the amount and intensity of women's speeches about women are not primarily driven by variations in the legislative agenda.
}

speech, particularly when large numbers of female MCs give emotionally intense speeches. Introducing controls (see Model 5.2) strengthens this interaction effect and also indicates that this relationship holds even after accounting for individual speakers' characteristics and the types of bills on the agenda.

To assess the substantive significance of our finding, Figure 1 plots the predicted values from Model 5.2. The $x$-axis shows the range of our Female Speeches variable (from 0 to 43 ). The $y$-axis plots the likelihood that a male MC's speech includes at least one Pearson and Dancey (2011b) term. We show average Female Pitch set to 2 standard deviations above and below its baseline in the solid and dashed lines, respectively.

From this figure, it is clear that as more female MCs take to the floor to give emotionally intense speeches about women, their male colleagues become more likely to mention women in their own speeches. For example, when Female Pitch is two standard deviations above its mean, going from the minimum number of female speeches referencing women (0) to the maximum (43) results in an increase in the likelihood that male MCs mention women from 0.05 to 0.56 . Yet, it is important to note that such an effect only occurs when the number of female speeches becomes quite large. Going from one standard deviation below (6) to one standard deviation above (11) the mean number of female speeches, yields only a $3 \%$ gain in the likelihood of a male $\mathrm{MC}$ referencing women (from 0.07 to 0.10 ). This underscores the hurdles female lawmakers face when trying to advance women's issues in the US House of Representatives. ${ }^{28}$

We next turn to investigating whether women's speeches might also influence the emotional intensity of male speeches referencing women (Table 6). Here, the main dependent variable is the vocal pitch of male MCs who spoke on the same day as women, scaled to standard deviations above and below their baseline. We are primarily interested in the interaction between (1) the number of female speeches using any of the Pearson and Dancey (2011b)'s terms (Female Speeches), (2) the average vocal pitch of those speeches (Female Pitch), and (3) whether a male MC mentioned women ("Women" Mentioned). If women's speeches increase not only the quantity, but also the emotional intensity, of male references to women, then we would expect this interaction term to be positive and statistically significant.

In Model 6.1, the interaction term is positive and statistically significant at the 0.05 -level. To help interpret this result, we present predicted values in Figure 2. When average female vocal pitch is set to two

\footnotetext{
${ }^{28}$ We re-estimated the models presented in Tables $1,5,6$, and 7 restricting our data to observations of vocal pitch \pm 2 standard deviations from a speaker's baseline. These results can be found on pages S66-S69 in the SI. Our results are generally robust to the elimination of extreme observations of vocal pitch.
} 
TABLE 5. The Quantity and Intensity of Women's Speech Affects the Quantity of Men's Speeches about Women

Dependent variable:

"Women" mentioned

(1)

\begin{tabular}{|c|c|c|}
\hline \multicolumn{3}{|l|}{ Fixed effects } \\
\hline Constant & $\begin{array}{c}-2.695^{\star \star \star} \\
(0.041)\end{array}$ & $\begin{array}{c}-2.237^{\star \star \star} \\
(0.220)\end{array}$ \\
\hline Female speeches & $\begin{array}{l}0.056^{\star \star \star} \\
(0.003)\end{array}$ & $\begin{array}{l}0.060^{\star \star \star} \\
(0.003)\end{array}$ \\
\hline Female pitch & $\begin{array}{l}-0.124^{\star \star \star} \\
(0.031)\end{array}$ & $\begin{array}{c}-0.129^{\star \star \star} \\
(0.032)\end{array}$ \\
\hline Democrat & & $\begin{array}{c}-0.334 \\
(0.250)\end{array}$ \\
\hline DW-nominate & & $\begin{array}{c}-0.525^{\star *} \\
(0.231)\end{array}$ \\
\hline Seniority & & $\begin{array}{l}-0.012^{\star \star \star} \\
(0.004)\end{array}$ \\
\hline Committee chair & & $\begin{array}{c}0.015 \\
(0.077)\end{array}$ \\
\hline White & & $\begin{array}{c}-0.180 \\
(0.147)\end{array}$ \\
\hline Women bills & & $\begin{array}{c}-0.022 \\
(0.028)\end{array}$ \\
\hline CQ bills & & $\begin{array}{c}-0.065^{\star *} \\
(0.030)\end{array}$ \\
\hline One minute & & $\begin{array}{c}-1.029^{\star * \star} \\
(0.051)\end{array}$ \\
\hline Duration & & $\begin{array}{l}0.086^{\star \star \star} \\
(0.004)\end{array}$ \\
\hline Election year & & $\begin{array}{l}0.136^{\star \star \star} \\
(0.034)\end{array}$ \\
\hline Female speeches $\times$ female pitch & $\begin{array}{c}0.009 \\
(0.005)\end{array}$ & $\begin{array}{l}0.011^{\star *} \\
(0.006)\end{array}$ \\
\hline $\begin{array}{l}\text { Random effects } \\
\text { MC }\end{array}$ & $\begin{array}{c}0.424 \\
(0.063)\end{array}$ & $\begin{array}{c}0.424 \\
(0.057)\end{array}$ \\
\hline $\begin{array}{l}N_{1} \\
N_{2} \\
\text { Log likelihood } \\
\text { AIC }\end{array}$ & $\begin{array}{c}50,235 \\
509 \\
-14,735.510 \\
29,481.010\end{array}$ & $\begin{array}{c}50,235 \\
509 \\
-13,950.230 \\
27,930.460\end{array}$ \\
\hline
\end{tabular}

standard deviations above the mean (1.41), increasing the number of female speeches mentioning women from one standard deviation below the mean (6) to one standard deviation above the mean (11) raises men's predicted vocal pitch when talking about women from 0.17 standard deviations to 0.26 standard deviations above their baseline. Increasing the number of female speeches mentioning women from the minimum $(0)$ to the maximum (43) raises men's predicted vocal pitch when talking about women from 0.12 standard deviations to 1.79 standard deviations above their baseline. This suggests that when female MCs deliver a large number of speeches on women with higher vocal pitch, male MCs are not only more likely to mention women but also do so with increased emotional intensity. ${ }^{29}$ These results hold even after the addition of a number of

\footnotetext{
${ }^{29}$ Since the majority of women in Congress are Democrats-and Democratic men may have more incentive to appeal to female voters (e.g., Chaturvedi 2016) - it is plausible that our results are contingent on male MCs' party. When we estimate separate models for Republican and Democratic men, however, we find that the speaking behavior of female lawmakers has a consistent effect on both groups of male MCs. This suggests that our results cannot be attributed to a single party (please refer to Section S7 in the Supplemental Information for additional details). At the same time, we acknowledge the possibility that only certain kinds of Republican (and Democratic) men are willing to engage with "women's issues," and that these male lawmakers may respond similarly to female MCs' speeches.
} 


\section{FIGURE 1. The Quantity and Intensity of Women's Speech Affects the Quantity of Men's Speeches} about Women

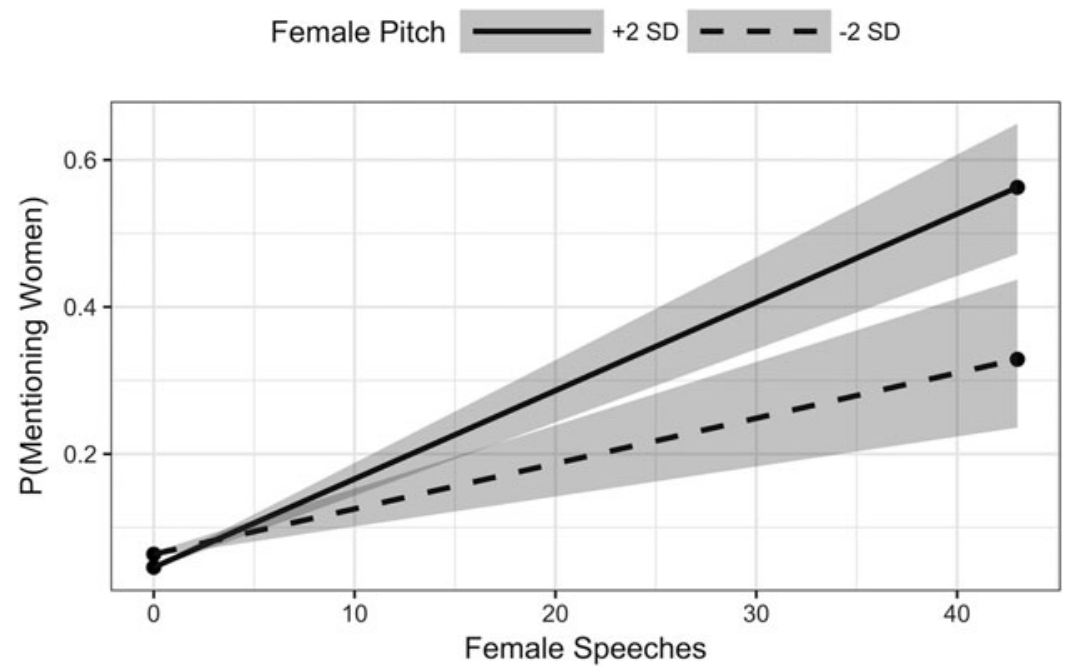

Note: Predicted male speaking behavior from Model 2 in Table 5 holding all other variables constant. Solid and dashed lines indicate $\mathrm{Fema}$ le Pitch was set to two standard deviations above (1.41) and below $(-1.28)$ the mean, respectively. On the $x$-axis, Female Speeches is allowed to vary from its minimum (0) to maximum (43). The $y$-axis is the probability that the male speech included any of the Pearson and Dancey $(2011$ b) women's dictionary terms. The gray ribbons represent $90 \%$ confidence intervals. The $95 \%$ confidence intervals overlap until the $x$-axis reaches approximately 25 speeches.

controls for legislator characteristics and the legislative agenda (see Table S14 on page S37 in the Supplemental Information). Together, this provides strong suggestive evidence of the link between female MCs' emotionally intense speeches about women and male MCs' speaking behavior.

\section{Voting Behavior}

Our results thus far are consistent with male MCs talking more about women, and with greater emotional intensity, when female lawmakers deliver a large number of emotionally intense speeches referencing women. On the one hand, these findings may represent (some) male legislators' desire to speak to women's concerns. In both judicial settings (Boyd, Epstein, and Martin 2010)-and in deliberation more generally (Karpowitz and Mendelberg 2014, 288) - when women talk, men listen. This can, in turn, alter group behavior and decisions. On the other hand, men's behavior could also reflect a backlash against female MCs' speeches. Past research has shown that as women become more prevalent in legislatures, male politicians act to minimize their influence to maintain dominance (Heath, Schwindt-Bayer, and Taylor-Robinson 2005; Kanthak and Krause 2012; Krook 2015), including becoming more aggressive and controlling of deliberation (Kathlene 1994). In this way, when female MCs take to the floor to deliver emotionally intense speeches, it could signal to male legislators that their dominance is under threat and thus result in an adverse reaction. We provide a preliminary examination of men's voting behavior to investigate whether changes in male MCs' speaking patterns can be better characterized as supportive of, or a backlash against, women's speech. To do so, we construct a measure of whether those Congressmen referencing women became more or less likely to vote with female MCs' who spoke about women on the House floor.

Estimating the relationship between women's speech and men's voting behavior is inherently difficult, as male legislators may be more likely to vote with female MCs who gave emotionally intense speeches about women simply because of shared ideology or partisanship. ${ }^{30}$ To overcome this challenge, our dependent variable in the models presented in Table 7 scales the proportion of male MC votes cast with female speakers based on their previous shared voting behavior. Our measure includes three components: (1) the proportion of votes male MCs cast in the same direction as the female speakers on a given legislative day, (2) the proportion of votes those male MCs typically cast with those same female speakers on all previous legislative days, and (3) the degree to which those proportions vary. Combining these three pieces of information yields a standardized measure where positive values indicate that male speakers were more likely to vote in line with female speakers than their past voting history would predict. Negative values indicate that male speakers were less likely to vote in line with female speakers, and would thus provide evidence of a backlash effect among those men who spoke with emotional intensity about women.

\footnotetext{
${ }^{30}$ We attempt to address this concern via our placebo tests, which are reported in Tables S29 and S30 on pages S61 and S62 in the Supplemental Information.
} 
TABLE 6. The Quantity and Intensity of Women's Speech Affects Men's Vocal Pitch

\begin{tabular}{|c|c|}
\hline & Dependent variable: \\
\hline & Male vocal pitch \\
\hline \multicolumn{2}{|l|}{ Fixed effects } \\
\hline Constant & $\begin{array}{l}-0.022^{\star \star \star} \\
(0.007)\end{array}$ \\
\hline "Women" mentioned & $\begin{array}{c}0.026 \\
(0.022)\end{array}$ \\
\hline Female speeches & $\begin{array}{l}0.003^{\star \star \star} \\
(0.001)\end{array}$ \\
\hline Female pitch & $\begin{array}{l}0.077^{\star * \star} \\
(0.009)\end{array}$ \\
\hline "Women" mentioned $\times$ Female speeches & $\begin{array}{c}-0.003 \\
(0.003)\end{array}$ \\
\hline Women" mentioned $\times$ Female pitch & $\begin{array}{c}0.004 \\
(0.031)\end{array}$ \\
\hline Female speeches $\times$ Female pitch & $\begin{array}{l}0.012^{\star * \star} \\
(0.002)\end{array}$ \\
\hline "Women" mentioned $\times$ Female speeches $\times$ female pitch & $\begin{array}{l}0.016^{\star * *} \\
(0.005)\end{array}$ \\
\hline $\begin{array}{l}\text { Random effects } \\
\text { MC }\end{array}$ & $\begin{array}{c}0.000 \\
(0.000)\end{array}$ \\
\hline $\begin{array}{l}N_{1} \\
N_{2} \\
\text { Log likelihood } \\
\text { AIC }\end{array}$ & $\begin{array}{c}49,914 \\
506 \\
-70,478.580 \\
140,977.200\end{array}$ \\
\hline
\end{tabular}

A detailed working example can be found on pages S36-S41 in the Supplemental Information. We also provide alternative model specifications that yield similar results on pages S41-S42. ${ }^{31}$ Likewise, a dyadic estimation of this relationship (and accompanying placebo tests) can be found in Section S8.2 of the Supplemental Information which starts on page S55.

The results of our model predicting male voting behavior can be found in Table 7. Because our primary variable of interest is the interaction term between Female Speeches and Female Pitch, we plot predicted percentage of co-voting in Figure 3. Model 7.2 shows a positive and statistically significant relationship between this interaction and the percentage of votes male MCs cast with female speakers. This provides evidence consistent with male legislators becoming more likely to vote with their female counterparts when women give a large number of emotionally intense speeches about women. When female MCs' average vocal pitch is set to two standard deviations above the mean (1.41) and women's speeches on women range from the minimum (0) to maximum (43), the rate at which male MCs vote with women on a given day increases from 0.23 standard deviations below to 0.53

\footnotetext{
${ }^{31}$ Unfortunately, we cannot say for sure whether votes take place after speeches. This is because there are no publicly available time stamps associated with specific votes. For example, Voteview data only include the date and vote number, not the time of day the vote occurred.
}

standard deviations above what we would expect given past voting behavior. ${ }^{32}$

Together, these results hint at the importance of women's collective speaking efforts. In the 111th-113th Congresses, there were between 77 and 81 women in the US House. The maximum number of female speeches we observe in our data (43) thus represents $56 \%$ of all women in the legislature taking to the floor to reference women. When we observe this high degree of women's participation, our models suggest that we are also likely to see men talk more (and with greater intensity) about women. And, our preliminary evidence indicates that they may be more likely to vote in line with those female speakers. This suggests that increasing women's descriptive representation in legislatures, particularly by electing female candidates who are champions of women, could help female representatives further advance the interests of women among their male colleagues.

At the same time, two caveats are in order. First, given the observational nature of our data, we do not claim that these findings reflect a causal relationship. Indeed, our aim is not to make claims about the effect of female MCs' emotionally intense speeches about women on

\footnotetext{
${ }^{32}$ We also estimated separate models for Democrats and Republicans. Table S21 reports these results on page S49 in the Supplemental Information. Predicted values are also plotted in Figure S11 which can be found on page S50. Collectively, these show that our general results hold within both parties.
} 
FIGURE 2. The Quantity and Intensity of Women's Speech Affects Men's Vocal Pitch

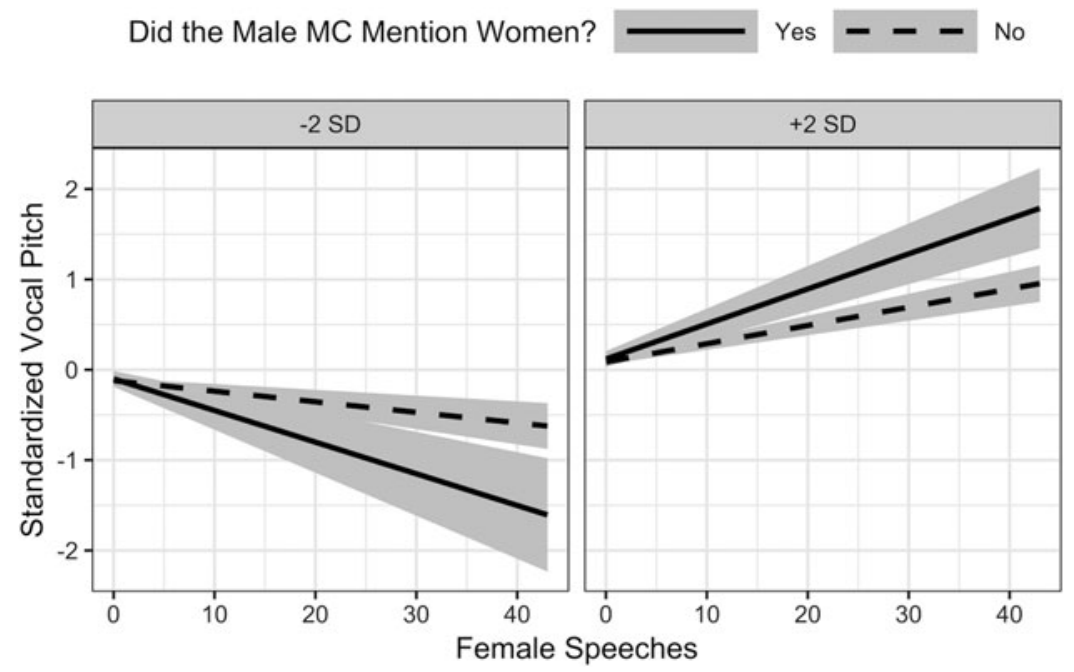

Note: Predicted vocal pitch derived from Model 2 in Table 6 holding all other variables constant. Solid lines indicate the speech included at least one of the Pearson and Dancey (2011b) women's dictionary terms. Dashed lines indicate all other speeches. For a given legislative day, Female Speeches is the total number of female speeches that used any of the Pearson and Dancey (2011b) women's dictionary terms and Female Pitch is the average vocal pitch of those speeches. Female speeches is allowed to vary from the minimum (0) to maximum (43), whereas Fema le Pitch is set to two standard deviations above (1.41) and below (-1.28) the mean in the right and left panel, respectively. The gray ribbons represent $95 \%$ confidence intervals.

men's voting behavior, but instead to simply determine whether men's heightened vocal pitch represents a backlash effect. Our examination of voting behavior yields no evidence of male backlash, which suggests that when Congresswomen speak with greater intensity about women, they do not encounter any immediate detrimental consequences. More generally, although we find an association between women's speeches and male MCs' behavior-and present dyadic models and placebo tests that lend further support to this relationship (see Section S8.2 of the Supplemental Information)-legislators' speeches on women simply cannot be randomly assigned. We thus cannot definitively rule out alternative explanations for this relationship.

Second, it is important to note that at lower levels of female floor participation, we see no positive (and sometimes negative) estimates of the effect of women's emotionally intense speech. This finding in some ways echoes the broader literature on gendered speaking behavior. Research focusing on ordinary citizens finds that women speak in a way that is characterized as more feminine than men, which includes speaking with more emotional content (Hogg 1985). Importantly, in mixed-gender settings, women often speak less than men (Karpowitz and Mendelberg 2014) and are perceived as less influential than their male counterparts (Carli, LaFleur, and Loeber 1995). Although there are important differences in elite women's speaking behavior as compared to ordinary citizens, our results suggest that when speaking alone, or in small numbers, Congresswomen may also find it difficult to achieve the standing and influence necessary to affect their male colleagues' behavior. Building on our preliminary findings, future work should thus explore the broader consequences of women's collective legislative efforts.

\section{CONCLUSIONS}

Despite the growth of research using text-as-data approaches, audio data have received scant attention from political scientists. Yet, audio archives are available for a growing number of legislative chambers, including some state legislatures and city councils in the United States and national assemblies abroad. Similar data also exist in other political settings, from courts and public hearings to candidate debates. Our work represents the first effort to harness this growing corpus of audio data to ask and answer questions about legislators' speech. In focusing our attention on vocal pitch and emotional activation, our findings provide new insights concerning both the emotional intensity of US lawmakers' speech and gendered speech dynamics. By highlighting the utility of audio-as-data approaches, we draw attention to a new way of studying political speech more broadly.

We argue that nonverbal components of legislators' floor speeches-in particular, small changes in a speaker's vocal pitch that are difficult to control-can shed new light on MCs' emotional intensity around a given issue area. Drawing on the well-established theoretical and empirical link between women's descriptive representation and activity on behalf of women, we focus on legislative speech addressing 
TABLE 7. The Quantity and Intensity of Women's Speech Affects Men's Voting Patterns

\begin{tabular}{|c|c|c|}
\hline & \multicolumn{2}{|c|}{ Dependent variable: } \\
\hline & \multicolumn{2}{|c|}{ Male votes cast } \\
\hline & (1) & $(2)$ \\
\hline \multicolumn{3}{|l|}{ Fixed effects } \\
\hline Constant & $\begin{array}{c}0.019 \\
(0.015)\end{array}$ & $\begin{array}{l}0.162^{\star \star} \\
(0.079)\end{array}$ \\
\hline Female speeches & $\begin{array}{c}0.001 \\
(0.001)\end{array}$ & $\begin{array}{l}0.0001 \\
(0.001)\end{array}$ \\
\hline Female pitch & $\begin{array}{l}-0.187^{\star \star *} \\
(0.013)\end{array}$ & $\begin{array}{l}-0.177^{\star * *} \\
(0.013)\end{array}$ \\
\hline Democrat & & $\begin{array}{r}-0.094 \\
(0.091)\end{array}$ \\
\hline DW-nominate & & $\begin{array}{r}-0.078 \\
(0.084)\end{array}$ \\
\hline Seniority & & $\begin{array}{c}-0.002 \\
(0.001)\end{array}$ \\
\hline Committee chair & & $\begin{array}{l}0.072^{\star \star} \\
(0.029)\end{array}$ \\
\hline White & & $\begin{array}{r}-0.055 \\
(0.051)\end{array}$ \\
\hline Women bills & & $\begin{array}{l}0.058^{\star \star \star} \\
(0.010)\end{array}$ \\
\hline CQ bills & & $\begin{array}{c}0.001 \\
(0.012)\end{array}$ \\
\hline One minute & & $\begin{array}{c}0.018 \\
(0.014)\end{array}$ \\
\hline Duration & & $\begin{array}{r}0.0001 \\
(0.002)\end{array}$ \\
\hline Election year & & $\begin{array}{c}-0.102^{\star \star \star} \\
(0.013)\end{array}$ \\
\hline Female speeches $\times$ female pitch & $\begin{array}{l}0.015^{\star \star \star} \\
(0.002)\end{array}$ & $\begin{array}{l}0.012^{\star \star \star} \\
(0.002)\end{array}$ \\
\hline $\begin{array}{l}\text { Random effects } \\
\text { MC }\end{array}$ & $\begin{array}{c}0.046 \\
(0.001)\end{array}$ & $\begin{array}{c}0.046 \\
(0.001)\end{array}$ \\
\hline $\begin{array}{l}N_{1} \\
N_{2} \\
\text { Log likelihood } \\
\text { AIC }\end{array}$ & $\begin{array}{c}21,920 \\
485 \\
-28,122.730 \\
56,257.460\end{array}$ & $\begin{array}{c}21,920 \\
485 \\
-28,106.130 \\
56,244.270\end{array}$ \\
\hline
\end{tabular}

women as an ideal application of our approach. Using almost 75,000 floor speeches given in the US House of Representatives, we show that women in Congress are not only more likely to discuss women on the floor, but also do so with greater emotional intensity. Our research thus both underscores and also extends our understanding of the importance of descriptive representation in legislatures. Although male MCs can and do represent women in Congress, female legislators are able to speak about women in a way that male lawmakers generally do not.

Our central finding suggests that small changes in vocal pitch can capture important information about legislators' emotional intensity. Our secondary analyses both indicate that increased vocal pitch is consistent with legislators' issue commitments and also draw attention to possible effects of emotionally intense speech. In our first extension, we offer two studies that provide important initial evidence that changes in vocal pitch correspond to other aspects of legislators' behavior. We show that the Congresswomen who are most emotionally activated when talking about women also receive significantly higher evaluations from women's interest groups as compared to the least activated female MCs. And, we show that Democrats and Republicans in Congress tend to become more emotionally activated when discussing policy issues owned by their respective parties. Taken together, these findings indicate that the emotional intensity legislators display in their floor speeches is not arbitrary, but is instead related to their underlying connection to the policy issue under debate. Extending our work further, 


\section{FIGURE 3. The Quantity and Intensity of Women's Speech Affects Men's Voting Patterns}



our second set of extensions suggest that lawmakers' emotionally intense speech may have a broader impact in the legislative chamber. There is a positive correlation between large numbers of women taking to the floor to talk about women with intensity and male legislators discussing women (and doing so with greater intensity).

Clearly, the nonverbal content of legislative speech provides information that is not captured by more overt measures of lawmakers' attitudes or commitments. Changes in vocal pitch are not explained, for example, by partisanship or D-W NOMINATE scores. And, when we examine other behaviors - such as legislators' interest group scores and men's vocal pitch and voting behavior - vocal pitch is a significant explanatory variable even when we control for these measures. Audio data also provide an opportunity to uncover information from legislative speeches that is lost in textas-data approaches. By incorporating vocal pitch into the study of legislators' behavior we gain information about the intensity (and perhaps impact) of representatives' words.

In highlighting vocal pitch as a measure of emotional intensity, our work also opens up new avenues of research with respect to legislative speech. Our extensions suggest that lawmakers who have long-standing commitments to a particular issue area tend to speak about that issue with higher vocal pitch. We expect that this logic could also apply to other groups of MCs. Veterans, doctors, and educators, for example, each likely draw heavily on personal experiences when discussing veterans' benefits, health policy, and education policy, respectively, on the floor of the US House. Analyzing audio data from the legislative speech of those group members would further validate the results from this paper. More generally, the novel method and data that we advance provide a measure that can potentially separate those who feel intensely about a policy from those who are simply responding to district or party demands.

Our analyses, moreover, have only scratched the surface of what can be learned from audio data. In this paper, we focus on emotional intensity both because it is substantively interesting and also because our measure of emotional activation is well established in the psychology literature. Yet, much more information can be gleaned from this data. Political scientists, for example, are already studying raw vocal pitch (e.g., Klofstad 2016). Scholars can also easily use audio data to examine other nonverbal measures. Researchers can analyze downward pitch contour as a proxy for disgust, as well as pitch variance within utterance (or total silence duration) as measures of anger. ${ }^{33}$ Indeed, a variety of audio variables have been used to identify specific emotional states (Banse and Scherer 1996). These measures, which can be computed from our data, could provide us with new perspectives on MCs' emotional reactions to their colleagues and to different issue areas. Moving beyond emotional intensity to measuring distinct emotional states would represent a significant step forward in the broader literature on emotions in politics.

An important future step for research involving audio data will be the development of tools to study vocal pitch at a more granular level than present techniques allow. Throughout our analyses, we have focused on mean fundamental frequency at the speech level. While much

\footnotetext{
${ }^{33}$ We thank an anonymous APSR referee for suggesting this point to us.
} 
can be gained from this approach, matching audio data to text at the word level is an intriguing potential avenue of future research. Although segmenting audio data into individual words poses significant methodological challenges, early work by Dietrich, O'Brien, and Yao (2019) posits interesting questions on intersectional identities that could benefit from more granular audio data.

Regardless of the results of this additional work, it is clear that floor speeches are an important tool for legislators. While it is easy to think of these speeches simply as collections of sentences and paragraphs, by examining the nonverbal behavior of MCs, we conceptualize the House floor as something more than words on a page. Our work allows scholars to view speeches as acts in which text, audio, and video come together to produce content that influences behavior within (and possibly beyond) Capitol Hill. Although speeches have long been acknowledged as valuable tools for understanding politicians' underlying ideological positions, we demonstrate that their nonverbal components yield insights into the intensity with which those positions are held.

\section{SUPPLEMENTARY MATERIAL}

To view supplementary material for this article, please visit https://doi.org/10.1017/S0003055419000467.

Replication materials can be found on Dataverse at: https://doi.org/10.7910/DVN/M4ARI7.

\section{REFERENCES}

Anderson, Rindy C., and Casey A. Klofstad. 2012. "Preference for Leaders with Masculine Voices Holds in the Case of Feminine Leadership Roles." PLoS One 7 (12): e51216.

Anderson, Rindy C., Casey A. Klofstad, William J. Mayew, and Mohan Venkatachalam. 2014. "Vocal Fry May Undermine the Success of Young Women in the Labor Market." PLoS One 9 (5): e97506.

Austen-Smith, David. 1990. "Information Transmission in Debate." American Journal of Political Science 34 (1): 124-52.

Bachorowski, Jo-Anne, and Michael J. Owren. 1995. "Vocal Expression of Emotion: Acoustic Properties of Speech Are Associated with Emotional Intensity and Context." Psychological Science 6 (4): 219-24.

Banse, Rainer, and Klaus R. Scherer. 1996. “Acoustic Profiles in Vocal Emotion Expression.” Journal of Personality and Social Psychology 70 (3): 614-36.

Bezooyen, Renee van. 1984. Characteristics of Vocal Expressions of Emotion. Dordrecht, Holland: Foris Publication.

Boersma, Paul. 1993. "Accurate Short-Term Analysis of the Fundamental Frequency and the Harmonics-To-Noise Ratio of a Sampled Sound." Proceedings of the Institute of Phonetic Sciences 17: 97-110.

Boyd, Christina L., Lee Epstein, and Andrew D. Martin. 2010. "Untangling the Causal Effects of Sex on Judging." American Journal of Political Science 54 (2): 389-411.

Brody, Leslie. 2009. Gender, Emotion, and the Family. Cambridge: Harvard University Press.

Burden, Barry C. 2007. Personal Roots of Representation. Princeton: Princeton University Press.

Carli, Linda L., Suzanne J. LaFleur, and Christopher C. Loeber. 1995. "Nonverbal Behavior, Gender, and Influene." Journal of Personality and Social Psychology 68 (6): 1030.
Carroll, Susan J. 2002. Representing Women: Congresswomen's Perceptions of Their Representational Roles. In Women Transforming Congress, ed. Cindy Simon Rosenthal. University of Oklahoma Press Norman, 50-68.

Chaturvedi, Richa. 2016. "A Closer Look at the Gender Gap in Presidential Voting." Pew Research July 28.

Clinton, Joshua, Simon Jackman, and Douglas Rivers. 2004. "The Statistical Analysis of Roll Call Data." American Political Science Review 98 (2): 355-70.

Davitz, Joel R. 1964. The Communication of Emotional Meaning. New York: McGraw Hill.

Debruyne, Frans, Wivine Decoster, Annemie Van Gijsel, and Julie Vercammen. 2002. "Speaking Fundamental Frequency in Monozygotic and Dizygotic Twins." Journal of Voice 16 (4): 466-71.

DePaulo, Bella M., James J. Lindsay, Brian E. Malone, Laura Muhlenbruck, Kelly Charlton, and Harris Cooper. 2003. "Cues to Deception.” Psychological Bulletin 129 (1): 74-118.

Diermeier, Daniel, Jean-François Godbout, Bei Yu, and Stefan Kaufmann. 2012. "Language and Ideology in Congress." British Journal of Political Science 42 (1): 31-55.

Dietrich, Bryce J., Diana O’Brien, and Jielu Yao. 2019. “Do Representatives Emphasize Some Groups More Than Others? Presented at the Annual Meeting of the Midwest Political Science Association. Chicago, IL: Midwest Political Science Association, $1-40$.

Dietrich, Bryce J., Ryan D. Enos, and Maya Sen. 2019. "Emotional Arousal Predicts Voting on the US Supreme Court." Political Analysis 27 (2): 237-43.

Ekman, Paul, Maureen O'Sullivan, Wallace V. Friesen, and Klaus R. Scherer. 1991. "Invited Article: Face, Voice, and Body in Detecting Deceit." Journal of Nonverbal Behavior 15 (2): 125-35.

Elkins, Aaron, Stefanos Zafeiriou, Maja Pantic, and Judee Burgoon. 2014. Unobtrusive Deception Detection. In The Oxford Handbook of Affective Computing, eds. Rafael A. Calvo, Sidney D'Mello, Johnathan Gratch, and Arvid Kappas. New York, NY: Oxford University Press chapter 38, 503-15.

Fenno, Richard F. 1977. "U.S. House Members in Their Constituencies: An Exploration." American Political Science Review 71 (3): 883-917.

Gerner, Deborah J., Philip A. Schrodt, Ronald A. Francisco, and Judith L. Weddle. 1994. "Machine Coding of Event Data Using Regional and International Sources." International Studies Quarterly 38 (1): 91-119.

Gerrity, Jessica C., Tracy Osborn, and Jeanette Morehouse Mendez. 2007. "Women and Representation: A Different View of the District?" Politics and Gender 3 (2): 179-200.

Goffman, Erving. 1959. Presentation of Self in Everyday Life. New York, NY: Anchor.

Goggin, Stephen N., and Alexander G. Theodoridis. 2017. "Disputed Ownership: Parties, Issues, and Traits in the Minds of Voters." Political Behavior 39 (3): 675-702.

Grimmer, Justin. 2013. Representational Style in Congress: What Legislators Say and Why It Matters. New York: Cambridge University Press.

Grimmer, Justin, and Brandon M. Stewart. 2013. "Text as Data: The Promise and Pitfalls of Automatic Content Analysis Methods for Political Texts." Political Analysis 21 (3): 267-97.

Hall, Judith A., Jason D. Carter, and Terrence G. Horgan. 2000. Gender Differences in Nonverbal Communication of Emotion. In Gender and Emotion: Social Psychological Perspectives, ed. Agneta Fischer. Cambridge: Cambridge University Press, 97-117.

Hall, Richard L. 1998. Participation in Congress. New Haven, CT: Yale University Press.

Harris, Douglas B. 2005. "Orchestrating Party Talk: A Party-Based View of One-Minute Speeches in the House of Representatives." Legislative Studies Quarterly 30 (1): 127-41.

Heath, Roseanna, Leslie A. Schwindt-Bayer, and Michelle M. TaylorRobinson. 2005. "Women on the Sidelines: Women's Representation on Committees in Latin American Legislatures." American Journal of Political Science 49 (2): 420-36.

Herrnson, Paul S., J. Celeste Lay, and Atiya Kai Stokes. 2003. "Women Running 'as Women': Candidate Gender, Campaign Issues, and Voter-Targeting Strategies." The Journal of Politics 65 (1): 244-55. 
Hogg, Michael A. 1985. "Masculine and Feminine Speech in Dyads and Groups: A Study of Speech Style and Gender Salience." Journal of Language and Social Psychology 4 (2): 99-112.

Hopkins, Daniel J., and Gary King. 2010. "A Method of Automated Nonparametric Content Analysis for Social Science." American Journal of Political Science 54 (1): 229-47.

Jones, Bryan D., Heather Larsen-Price, and John Wilkerson. 2009. "Representation and American Governing Institutions." The Journal of Politics 71 (1): 277-90.

Kanthak, Kristin, and George A. Krause. 2012. The Diversity Paradox: Political Parties, Legislatures, and the Organizational Foundations of Representation in America. New York: Oxford University Press.

Karpowitz, Christopher F., and Tali Mendelberg. 2014. The Silent Sex: Gender, Deliberation, and Institutions. Princeton: Princeton University Press.

Kathlene, Lyn. 1994. "Power and Influence in State Legislative Policymaking: The Interaction of Gender and Position in Committee Hearing Debates." American Political Science Review 88 (3): 560-76.

Kathlene, Lyn. 1995. "Alternative Views of Crime: Legislative Policymaking in Gendered Terms." The Journal of Politics 57 (3): 696-723.

King, Gary, and Will Lowe. 2003. "An Automated Information Extraction Tool for International Conflict Data with Performance as Good as Human Coders: A Rare Events Evaluation Design." International Organization 57 (3): 617-42.

Kingdon, John W. 1989. Congressmen's Voting Decisions. Ann Arbor, MI: University of Michigan Press.

Klofstad, Casey A. 2016. "Candidate Voice Pitch Influences Election Outcomes." Political Psychology 37 (5): 725-38.

Klofstad, Casey A., Rindy C. Anderson, and Stephen Nowicki. 2015. "Perceptions of Competence, Strength, and Age Influence Voters to Select Leaders with Lower-Pitched Voices." PLoS One 10 (8): e0133779.

Klofstad, Casey A., Rindy C. Anderson, and Susan Peters. 2012. "Sounds Like a Winner: Voice Pitch Influences Perception of Leadership Capacity in Both Men and Women." Proceedings of the Royal Society of London B Biological Sciences 279 (1738): 2698-704.

Kraut, Robert E. 1978. "Verbal and Nonverbal Cues in the Perception of Lying." Journal of Personality and Social Psychology 36 (4): 380-91.

Krook, Mona Lena. 2015. "Empowerment versus Backlash: Gender Quotas and Critical Mass Theory." Politics, Groups, and Identities 3 (1): 184-8.

Laukka, Petri, Patrik Juslin, and Roberto Bresin. 2005. "A Dimensional Approach to Vocal Expression of Emotion." Cognition \& Emotion 19 (5): 633-53.

Laver, Michael, Kenneth Benoit, and John Garry. 2003. "Extracting Policy Positions from Political Texts Using Words as Data." American Political Science Review 97 (2): 311-31.

Levy, Dena, Charles Tien, and Rachelle Aved. 2001. "Do Differences Matter? Women Members of Congress and the Hyde Amendment." Women \& Politics 23 (1): 105-27.

Maltzman, Forrest, and Lee Sigelman. 1996. "The Politics of Talk: Unconstrained Floor Time in the U.S. House of Representatives." The Journal of Politics 58 (3): 819-30.

Mansbridge, Jane. 1999. "Should Blacks Represent Blacks and Women Represent Women? A Contingent 'Yes'." The Journal of Politics 61 (3): 628-57.

Mauss, Iris B., and Michael D. Robinson. 2009. "Measures of Emotion: A Review." Cognition \& Emotion 23 (2): 209-37.

Mayhew, David R. 1974. Congress: The Electoral Connection. New Haven, CT: Yale University Press.

Mendelberg, Tali, Christopher F. Karpowitz, and J. Baxter Oliphant. 2014. "Gender Inequality in Deliberation: Unpacking the Black Box of Interaction." Perspectives on Politics 12 (1): 18-44.

Morris, Jonathan S. 2001. "Reexamining the Politics of Talk: Partisan Rhetoric in the 104th House." Legislative Studies Quarterly 26 (1): $101-21$.

Osborn, Tracy, and Jeanette Morehouse Mendez. 2010. "Speaking as Women: Women and Floor Speeches in the Senate." Journal of Women, Politics \& Policy 31 (1): 1-21.

Owren, Michael J., and Jo-Anne Bachorowski. 2007. Measuring Emotion-Related Vocal Acoustics. In Handbook of Emotion
Elicitation and Assessment, eds. James A. Coan and John J. B. Allen. New York, NY: Oxford University Press, 239-65.

Pearson, Kathryn, and Logan Dancey. 2011a. "Elevating Women's Voices in Congress Speech Participation in the House of Representatives." Political Research Quarterly 64 (4): 910-23.

Pearson, Kathryn, and Logan Dancey. 2011b. "Speaking for the Underrepresented in the House of Representatives: Voicing Women's Interests in a Partisan Era." Politics and Gender 7 (4): 493-519.

Petrocik, John R. 1996. "Issue Ownership in Presidential Elections, with a 1980 Case Study." American Journal of Political Science 40 (3): 825-50.

Petrocik, John R., William L. Benoit, and Glenn J. Hansen. 2003. "Issue Ownership and Presidential Campaigning, 1952-2000." Political Science Quarterly 118 (4): 599-626.

Poole, Keith T., and Howard Rosenthal. 1985. "A Spatial Model for Legislative Roll Call Analysis." American Journal of Political Science 29 (2): 357-84.

Poole, Keith T., and Howard Rosenthal. 2001. "D-nominate after 10 Years: A Comparative Update to Congress." Legislative Studies Quarterly 26 (1): 5-29.

Proksch, Sven-Oliver, and Jonathan B. Slapin. 2012. "Institutional Foundations of Legislative Speech." American Journal of Political Science 56 (3): 520-37.

Przybyla, Beata D., Yoshiyuki Horii, and Michael H. Crawford. 1992. "Vocal Fundamental Frequency in a Twin Sample: Looking for a Genetic Effect." Journal of Voice 6 (3): 261-6.

Puts, David Andrew, Steven J. C. Gaulin, and Katherine Verdolini. 2006. "Dominance and the Evolution of Sexual Dimorphism in Human Voice Pitch." Evolution and Human Behavior 27: 283-96.

Quinn, Kevin M., Burt L. Monroe, Michael Colaresi, Michael H. Crespin, and Dragomir R. Radev. 2010. "How to Analyze Political Attention with Minimal Assumptions and Costs." American Journal of Political Science 54 (1): 209-28.

Reingold, Beth. 1992. "Concepts of Representation Among Female and Male State Legislators." Legislative Studies Quarterly 17 (4): 509-37.

Roberts, Margaret E., Brandon M. Stewart, and Dustin Tingley. 2014. "Stm: R Package for Structural Topic Models." R Package 1: 1-12.

Roberts, Margaret E., Brandon M. Stewart, Dustin Tingley, Christopher Lucas, Jetson Leder-Luis, Shana Kushner Gadarian, Bethany Albertson, and David G. Rand. 2014. "Structural Topic Models for Open-Ended Survey Responses." American Journal of Political Science 58 (4): 1064-82.

Roberts, Margaret E., Brandon M. Stewart, Dustin Tingley, and Edoardo M. Airoldi. 2013. The Structural Topic Model and Applied Social Science. In Advances in Neural Information Processing Systems Workshop on Topic Models: Computation, Application, and Evaluation.

Russell, James A. 1980. “A Circumplex Model of Affect.” Journal of Personality and Social Psychology 39 (6): 1161.

Scherer, Klaus R. 2013. "Vocal Markers of Emotion: Comparing Induction and Acting Elicitation." Computer Speech \& Language 27 (1): 40-58.

Schiller, Wendy J. 1995. "Senators as Political Entrepreneurs: Using Bill Sponsorship to Shape Legislative Agendas." American Journal of Political Science 39 (1): 186-203.

Schuller, Björn, Anton Batliner, Stefan Steidl, and Dino Seppi. 2011. "Recognising Realistic Emotions and Affect in Speech: State of the Art and Lessons Learnt from the First Challenge." Speech Communication 53 (9-10): 1062-87.

Shogan, Colleen J. 2001. "Speaking Out." Women \& Politics 23 (1): 129-46.

Snyder, James M., and Tim Groseclose. 2000. "Estimating Party Influence in Congressional Roll-Call Voting." American Journal of Political Science 44 (2): 193-211.

Stewart, Charles III, and Jonathan Woon. 2016. Congressional Committee Assignments, 103rd to 114th Congresses, 1993-2017: House. Cambridge: Massachusetts Institute of Technology.

Sulkin, Tracy. 2005. Issue Politics in Congress. New York: Cambridge University Press.

Swers, Michele L. 2002. The Difference Women Make: The Policy Impact of Women in Congress. Chicago, IL: University of Chicago Press. 
Titze, Ingo R. 2000. Principles of Voice Production. Iowa City, IA: National Center for Voice and Speech.

Volden, Craig, Alan E. Wiseman, and Dana E. Wittmer. 2018. "Women's Issues and Their Fates in the US Congress." Political Science Research and Methods 6 (4): 679-96.

Walsh, Katherine Cramer. 2002. Enlarging Representation: Women Bringing Marginalized Perspectives to Floor Debate in the House of Representatives. In Women Transforming Congress, ed. Cindy
Simon Rosenthal. Norman, OK: University of Oklahoma Press, 370-96.

Woon, Jonathan. 2009. "Issue Attention and Legislative Proposals in the US Senate." Legislative Studies Quarterly 34 (1): 29-54.

Zuckerman, Miron, and Robert E. Driver. 1985. Telling Lies: Verbal and Nonverbal Correlates of Deception. In Multichannel Integrations of Nonverbal Behavior, eds. Aaron W. Siegman and Stanley Feldstein. New York, NY: Lawrence Erlbaum, chapter 3, 129-47. 